\title{
Polyphenism in social insects: insights from a transcriptome-wide analysis of gene expression in the life stages of the key pollinator, Bombus terrestris
}

Thomas J Colgan ${ }^{1 *}$, James C Carolan ${ }^{1,2}$, Stephen J Bridgett ${ }^{3}$, Seirian Sumner ${ }^{4}$, Mark L Blaxter ${ }^{3,5}$ and Mark JF Brown $n^{1,6}$

\begin{abstract}
Background: Understanding polyphenism, the ability of a single genome to express multiple morphologically and behaviourally distinct phenotypes, is an important goal for evolutionary and developmental biology. Polyphenism has been key to the evolution of the Hymenoptera, and particularly the social Hymenoptera where the genome of a single species regulates distinct larval stages, sexual dimorphism and physical castes within the female sex. Transcriptomic analyses of social Hymenoptera will therefore provide unique insights into how changes in gene expression underlie such complexity. Here we describe gene expression in individual specimens of the pre-adult stages, sexes and castes of the key pollinator, the buff-tailed bumblebee Bombus terrestris.
\end{abstract}

Results: CDNA was prepared from mRNA from five life cycle stages (one larva, one pupa, one male, one gyne and two workers) and a total of 1,610,742 expressed sequence tags (ESTs) were generated using Roche 454 technology, substantially increasing the sequence data available for this important species. Overlapping ESTs were assembled into 36,354 B. terrestris putative transcripts, and functionally annotated. A preliminary assessment of differences in gene expression across non-replicated specimens from the pre-adult stages, castes and sexes was performed using R-STAT analysis. Individual samples from the life cycle stages of the bumblebee differed in the expression of a wide array of genes, including genes involved in amino acid storage, metabolism, immunity and olfaction.

Conclusions: Detailed analyses of immune and olfaction gene expression across phenotypes demonstrated how transcriptomic analyses can inform our understanding of processes central to the biology of $B$. terrestris and the social Hymenoptera in general. For example, examination of immunity-related genes identified high conservation of important immunity pathway components across individual specimens from the life cycle stages while olfactory-related genes exhibited differential expression with a wider repertoire of gene expression within adults, especially sexuals, in comparison to immature stages. As there is an absence of replication across the samples, the results of this study are preliminary but provide a number of candidate genes which may be related to distinct phenotypic stage expression. This comprehensive transcriptome catalogue will provide an important gene discovery resource for directed programmes in ecology, evolution and conservation of a key pollinator.

\footnotetext{
* Correspondence: tcolgan@tcd.ie

'Department of Zoology, School of Natural Sciences, Trinity College Dublin,

Dublin 2, Ireland

Full list of author information is available at the end of the article
} 


\section{Background}

A major problem in biology is understanding phenotypic plasticity. Phenotypic plasticity, the ability of a single genotype to express alternative forms of morphology, physiology and behaviour in response to environmental conditions [1], provides the opportunity to study the influences of environment on the genome of an individual or group. Within the natural world, phenotypic plasticity is widespread and has been key to speciation and evolution [1-3]. However, within eusocial species it has resulted in polyphenism, where multiple distinct adult phenotypes result from differential expression of a single genome [4]. Revealing how multiple sets of genes are differentially expressed within the distinct phenotypes of eusocial species offers an unprecedented opportunity to understand the molecular mechanisms related to polyphenisms.

The eusocial Hymenoptera (ants, some bees and wasps) present an excellent system in which to study how gene expression relates to numerous types of polyphenism. Firstly, the social Hymenoptera undergo complete metamorphosis, or holometabolous development, where four morphologically distinct developmental stages (egg, larva, pupa and adult) exist. Holometabolous development is widespread in the superorder Endopterygota and the success of the life history trait is reflected in the high rates of diversification of species that undergo complete metamorphosis [5]. Secondly, they possess caste differentiation within the female sex, where a clear division of labour is evident between two or more physiologically, behaviourally and, in many cases, morphologically distinct phenotypes $[6,7]$. The reproductive duties of the colony are dominated by a queen while the majority of individuals serve as functionally sterile workers that perform altruistic tasks such as larval feeding, resource foraging, nest maintenance and colony defence [8]. Third, social Hymenoptera display haplodiploid sex determination, with females produced from diploid eggs, while haploid eggs develop into males [9].

Transcriptomic studies have the potential to unveil key gene expression differences that govern central biological processes, such as immunity and olfaction, within and across life cycle stages. A number of studies have been performed in social Hymenoptera to determine which genes are differentially expressed across the adult castes [10-16] and across the sexes [17-19]. These analyses addressed only subsets of the complete transcriptomes of the target species. Recent advances in sequencing technology, such as Roche 454 and Illumina sequencing platforms, generate vastly higher volumes of data $[20,21]$. As a consequence, these technologies have been used in several studies of non-model species, such as the Granville butterfly [22], the Propertius duskywing and the Anise swallowtail butterflies [23], the migratory locust Locusta migratoria [24] and the primitively eusocial wasp, Polistes metricus [25]. These studies demonstrate the potential of transcriptomics to provide insights into the expression of polyphenisms in insects, including eusocial species. Thus, the utilisation of transcriptomic tools can significantly improve our knowledge of what genes influence the evolution of polyphenism within eusocial insect species.

The buff-tailed bumblebee Bombus terrestris, which is common across Eurasia, is an important ecological pollinator of a wide variety of crops $[26,27]$. The success of $B$. terrestris as a pollinator is reflected in its increased utilisation in commercial agriculture, a multi-million dollar industry [28]. Caste differentiation in the female sex is evident in $B$. terrestris with a single monandrous queen responsible for the main reproductive duties of the colony while functionally sterile workers perform altruistic tasks. As in all social Hymenoptera, sex determination is haplodiploid. B. terrestris has an annual life cycle, where queens overwinter for several months, postmating. Post-hibernation, the overwintered queen establishes a colony in early Spring. She constructs the initial nest, and lays eggs. These hatch after four days into larvae that are completely dependent for feeding from the queen or sister workers for 10 to 14 days [29]. After spinning a cocoon or pupal case, the larva pupates for approximately fourteen days and metamorphoses into the adult [26]. Bombus workers display a range of sizes, with size being correlated to function, such as larger bees functioning as foragers [30]. Worker-destined diploid eggs continue to be laid by the queen until a transition point occurs during the colony life cycle, known as the competition phase, where the workers begin to develop functional ovaries and compete with the queen for reproductive output. Workers lay unfertilised male-destined haploid eggs. The initiation of the competition phase coincides with haploid egg laying by the queen while diploid eggs present in the nest may develop into gynes, or virgin queens. Sexuals leave the colony soon after emergence. Virgin queens are mated and subsequently, locate a suitable site to diapause for the duration of the winter months [26].

Two previous transcriptomic studies for B. terrestris have been performed. Sadd et al. [31] generated 29,428 expressed sequence tags (ESTs) from the thorax and abdomen of four pooled workers ( 2 were seven days post-emergence while the second 2 were aged fourteen days post-emergence) using Sanger sequencing technology. More recently, Woodard et al. [32] generated 454 reads from the brains and abdomens of over 50 workers, to include in an analysis of genes central to convergent 
evolution of eusociality within the bees. While both studies have provided valuable resources for the study of the genomics of $B$. terrestris, they focused on gene expression within workers and as genes may be differentially regulated throughout development, caste or sex, a study incorporating multiple life cycle stages is required to increase our knowledge of gene expression in this important pollinator.

Here we present a deep-sequencing Roche 454 transcriptome study of the pre-adult stages, adult castes, and sexes of $B$. terrestris, based on individual specimens. We identify potentially differentially expressed transcripts related to polyphenism and use differential expression to explore hypotheses for the involvement of two important biological processes, immunity and olfaction, in the life cycle of the bee. These processes were chosen because they represent generally important aspects of animal biology, they are expected to exhibit specific patterns of differential expression in social insects, and they can act as exemplars for the power of the transcriptomic approach. Immune defence against foreign agents would be expected to be heightened in life cycle stages that are more prone to infection, such as larvae, which are housed in a homeostatic nest environment with a high density of nest-mates and consumable resources [33], compared to those that are more protected, such as pupae, which are enclosed in a sealed cocoon. In adults, workers, which have increased exposure to the environment through foraging and increased contact with potentially infected individuals in the colony, and gynes, which need to survive mating and hibernation, would require a heightened immune response to increase longevity compared to the non-social short-lived male [34-36]. Olfaction is a key aspect of animal biology, and in Bombus is particularly important for nest-mate recognition and communication [37], resource discrimination [38], subordinate control by the queen [39] and also mate selection [40]. We thus predict that specific olfaction-related genes would be upregulated in the adult stages, for purposes of resource discrimination and mate recognition, while distinct repertoires will be active in pre-adult stages, for caste-development pheromone reception.

\section{Results}

Sequencing, assembly and assembly validation

Six cDNA preparations were sequenced using the Roche 454 Life Sciences GS FLX Titanium Series sequencer, generating a total of 1,610,742 sequences. After removal of adapters and poly(A) tails, and trimming for base quality, there were $1,560,873$ high quality sequences with an average length of 323 bases. Using the method outlined by Kumar and Blaxter [41], these were assembled using two different assemblers, Roche 454's
gsAssembler ("Newbler") and MIRA, to generate the first-order assemblies that we will refer to as Newbler_454 and MIRA_454. There were 38,212 contigs in Newbler_454 with a mean length of 650 bases, while MIRA_454 contained 65,786 with a mean length of 668 bases (detailed assembly information is provided in Additional file 1). Using PartiGene, 29,428 B. terrestris Sanger ESTs generated by Sadd et al. [31] and 234 $B$. terrestris mRNA sequences (obtained from EMBL nucleotide database) were clustered into 12,337 contigs (hereafter referred to as PG_Sanger). The three first order assemblies (PG_Sanger, Newbler_454 and MIRA_454) were coassembled using CAP3 to generate the BT_transcriptome_v1 contig set. This contained 22,318 contigs with contributions from more than one first order contig, of which 4,867 had contributions from all three first order assemblies, and 33,819 additional contigs containing single first order contigs (Figure 1). As expected, the improved data sampling in terms of depth, life cycle stage, caste and sex resulted in there being an excess (14,675 contigs) of CAP3 contigs with contribution from only Newbler_454 and MIRA_454. We regard those contigs with independent evidence from Sanger and 454 data, and presence in all three primary assemblies as being highly credible. CAP3 contigs with contributions from two or only one primary assembly are likely to be of lower credibility.

We noted that there was still some residual redundancy in BT_transcriptome_v1 contig set, and thus reclustered using the 56,137 second order contigs with PartiGene (removing 1,249 contigs with length of 100 bases or less). This dataset, BT_transcriptome_v2, contained 36,354 contigs. Of these, 25,886 were unchanged from BT_transcriptome_v1, while the remaining 29,210 BT_transcriptome_v1 contigs were clustered into 10,468 BT_transcriptome_v2 contigs. BT_transcriptome_v2 contigs have an average length of 1,102 bases (minimum length $=100$ bases, maximum length $=26,105$ bases) with an N50 contig size of 1,533 bases. The total span of the BT_transcriptome_v2 contigs is $40 \mathrm{MB}$. Full details of the assembly are provided in Additional file 1.

PG_Sanger contigs that did not coassemble with the 454 primary assemblies were examined for biological credibility. Approximately $75 \%(22,142)$ of the B. terrestris Sanger sequences were included in contigs with 454 data while in comparison, 862,818 (55\% of total high quality screened reads) 454 reads mapped to the PG_Sanger contigs. The remaining 7,519 Sanger sequences clustered into 5,266 contigs, of which 4,091 (77\%) were singletons. Thus we conclude that the Sanger-sequencing derived contigs that lack 454 data support are more likely to be rarely expressed genes or technical artefacts. However, AT content was approximately equal for both sets $(63.8 \%$ for Sanger-only 


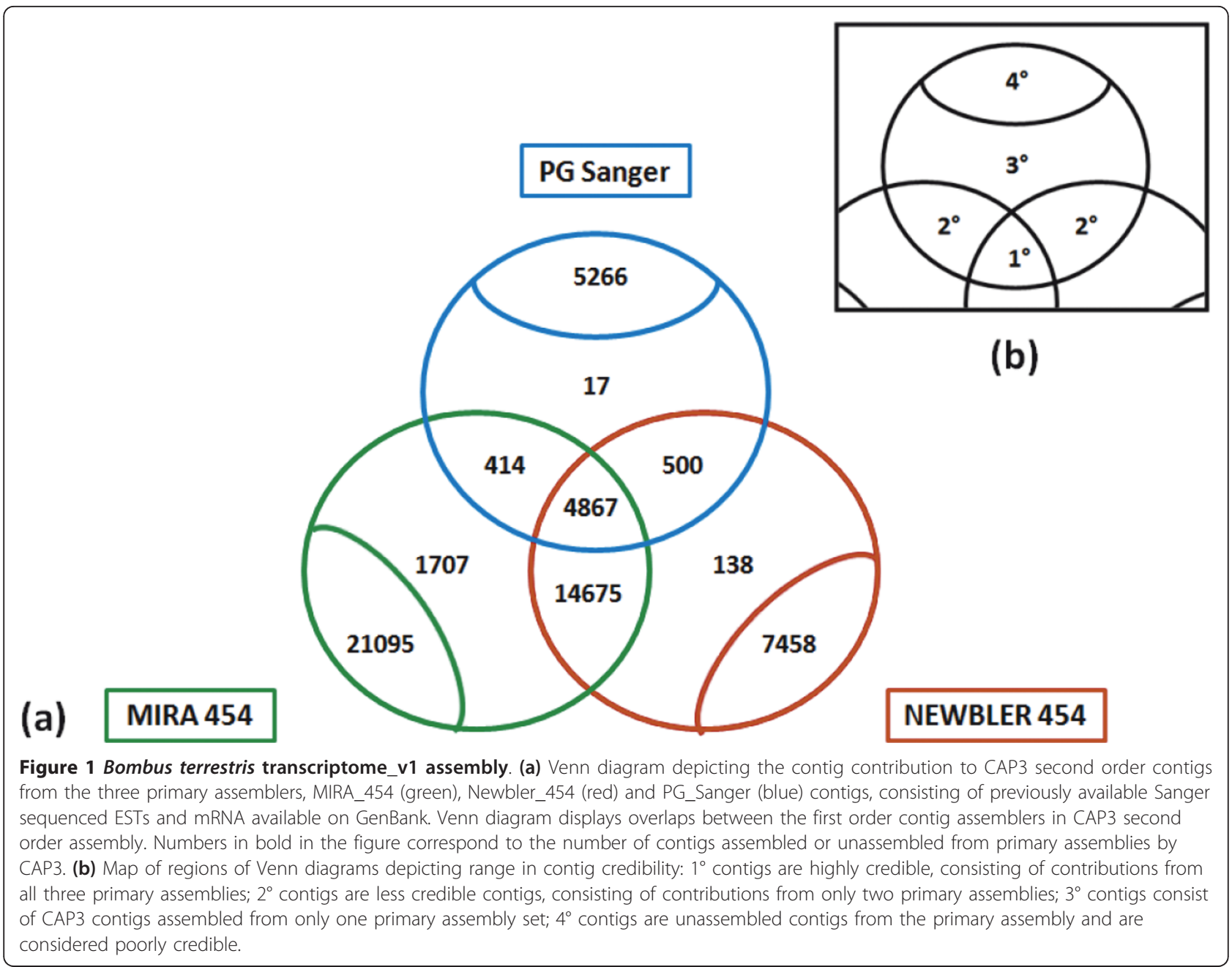

compared to $64 \%$ for those that coassembled with 454), suggesting that these isolated contigs do not derive from genomic contamination. In terms of gene content, $43 \%$ of the 5,266 Sanger-only contigs had significant (BLASTx E-value < 1e-6) matches to the nonredundant protein database, again suggesting that many have recognisable coding potential and are less likely to be artefacts. Full information on testing of credibility is provided in Additional file 2.

The B. terrestris genome project has released a first draft assembly and $95.9 \%$ of the BT_transcriptome_v2 contigs $(\mathrm{n}=34,861)$ had high significance megablast matches $(E$-value $<1 \mathrm{e}-65)$ to these data. Woodard et al. [32] generated an assembly of 19,485 B. terrestris contigs from Roche 454 data derived from sampling the brains and abdomens of over 50 bees, which were obtained from the TSA database on NCBI. Nearly $75 \%$ of these contigs $(14,576)$ matched 9,003 contigs within BT_transcriptome_v2. The contigs unique to the study of Woodard et al. [32] may derive from rare transcripts, or from differences in origin of samples as Woodard et al. [32] generated transcripts from only brains and abdomens of workers while we used whole bodies of several stages.

\section{Annotation of BT_transcriptome_v2}

We compared BT_transcriptome_v2 to the NCBI nr protein database and found significant matches (BLASTx, with E-value cut-off of 1e-06) for $57.8 \%$ (n = 21,028) contigs (Figure 2). Of these contigs, 14,268 were assembled from more than one first order assembly. Based on the fact that these contigs were independently assembled using two different algorithms, we may have greater confidence in the biological validity of these 14,268 contigs. The majority of top-scoring matches (20,958 or $57.6 \%)$ were to Hymenoptera, including Apis species (36.4\% of all contigs), the ant species Harpegnathos saltator (5.7\%), Camponotus floridanus (5.5\%) and Solenopsis invicta (3.4\%), the parasitoid wasp Nasonia species (1.7\%) and Bombus species (1.1\%) (the 


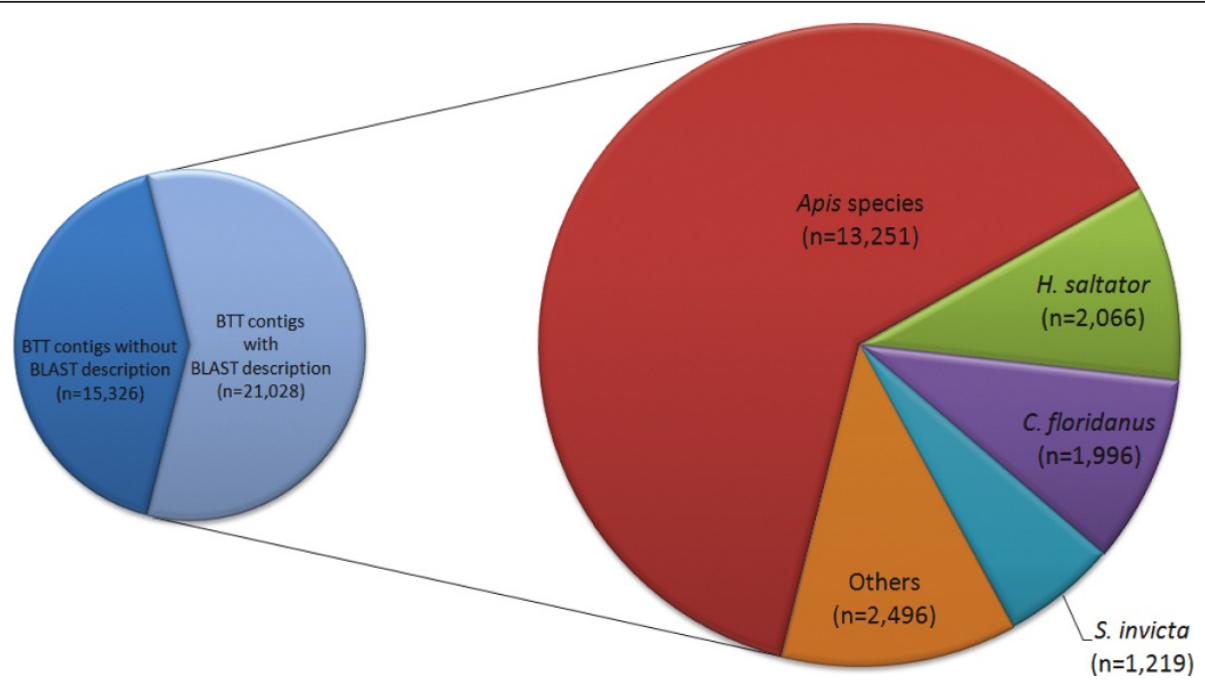

Figure 2 Pie-chart displaying the species distribution for top BLAST match for BT_transcriptome_v2 contig set against NCBI nr database. BLASTx, E-value cut-off of 1e-06, against NCBI nonredundant database generated putative matches for 21,028 B. terrestris sequences. Species generating the most putative matches were Hymenopteran insects: 13,251 (Apis species); 2,066 (C. floridanus); 1,996 (H. saltator); 1,219 (S. invicta); 608 (Nasonia species); and 410 (Bombus species). Others account for 1,478 putative BLAST matches for BT_transcriptome_v2 contigs.

proportional representation reflecting the available protein sequence data). We compared the transcriptome assembly to the whole-genome derived proteomes of a set of model Hymenoptera and other insects. Of the 36,354 BT_transcriptome_v2 contigs, 19,744 (54.3\%) matched a predicted protein from the honeybee Apis mellifera genome, 19,640 (54.0\%) matched predicted proteins in the ant C. floridanus, and 19,762 (54.4\%) matched predicted proteins in the ant H. saltator. There were 14,258 (39.2\%) matches to the Drosophila melanogaster transcriptome. To generate a gene estimate for our BT_transcriptome_v2 contig set, we examined the amount of best BLAST matches (tBLASTx cut-off of 1e10) between our transcriptome set and the OGS of the honeybee, $A$. mellifera. In total, the BT_transccriptome_v2 contig set matched 9, 217 unique predicted proteins from the latest Apis genome OGS suggesting the potential for an equal number of homologous proteinencoding genes within our transcriptome set. Contigs that had no match to a previously predicted protein may derive from non-coding RNAs, untranslated regions of mRNAs, or from protein coding genes highly diverged in or novel to B. terrestris.

Functional annotation classification using the GO, EC and KEGG ontologies using annot8r resulted in the assignment of 533,897 GO terms, 14,345 EC terms and 47,355 KEGG terms to BT_transcriptome_v2 contigs. Approximately $39 \%(n=13,996)$ of contigs were annotated with GO terms. While many other contigs had significant BLAST matches in protein databases, these were to genes that have no GO annotation. GO-Slim analyses are provided in Additional file 3. InterProScan searches were performed generating predicted protein signatures for 24,998 BT_transcriptome_v2 contigs, of which 10,358 contigs received InterProScan (IPR) annotations with information regarding protein family, occurrences of functional domains and repeats. 14,640 contigs had no IPR annotation but were annotated with functional domains.

\section{Conservation of major biological processes and pathways across Insecta}

To assess the completeness of the B. terrestris transcriptome represented in our data, we investigated the presence in BT_transcriptome_v2 of genes in conserved developmental and physiological pathways across a set of sequenced insect genomes. For each pathway or system, a set of canonical genes was collated from the proteomes of four species (the eusocial hymenopteran, $A$. mellifera, the solitary hymenopteran, Nasonia vitripennis, the holometabolous dipteran, D. melanogaster, and the hemimetabolous hemipteran, Acyrthosiphon pisum; see Additional file 4) and these were compared to BT_transcriptome_v2 (Table 1). For each species, between $98.5 \%$ and $96.7 \%$ of the surveyed genes had matches in BT_transcriptome_v2, suggesting that deep sequencing with 454 technology has indeed yielded comprehensive insight into the core regulatory machinery in B. terrestris.

\section{Life cycle differential expression in B. terrestris}

We estimated the expression level of each contig by counting 454 reads mapped back to the BT_transcriptome_v2 dataset. The majority $(1,441,743$ ESTs or $92.4 \%)$ 
Table 1 Conservation of biological processes and pathways across Insecta.

\begin{tabular}{|c|c|c|c|c|}
\hline Biological Processes and Pathways & A. mellifera & N. vitripennis & D. melanogaster & A. pisum \\
\hline \multicolumn{5}{|l|}{ Development } \\
\hline Dorsoventral Axis Formation & $21(22)$ & $10(10)$ & $63(65)$ & $17(17)$ \\
\hline Progesterone mediated oocyte maturation & $50(50)$ & $41(41)$ & $59(59)$ & $37(39)$ \\
\hline \multicolumn{5}{|l|}{ Developmental Signalling Pathways } \\
\hline Decapentaplegic & $21(22)$ & $19(19)$ & $33(34)$ & $23(24)$ \\
\hline Hedgehog & $23(25)$ & $24(25)$ & $36(37)$ & $15(15)$ \\
\hline Notch & $16(17)$ & $18(18)$ & $31(32)$ & $18(19)$ \\
\hline Wnt & $62(63)$ & $60(60)$ & $118(119)$ & $49(50)$ \\
\hline \multicolumn{5}{|l|}{ Metabolism } \\
\hline Metabolic Pathways & $526(532)$ & $497(508)$ & $1118(1169)$ & $528(533)$ \\
\hline \multicolumn{5}{|l|}{ Physiology } \\
\hline Circadian rhythm & $6(7)$ & $7(7)$ & $31(36)$ & $8(8)$ \\
\hline JAK-STAT & $13(14)$ & $11(12)$ & * & $17(17)$ \\
\hline MAPK & $9(11)$ & $6(7)$ & $25(28)$ & $15(17)$ \\
\hline mTOR & $23(23)$ & $20(20)$ & $42(43)$ & $25(25)$ \\
\hline Neuroactive-ligand binding receptor & $27(29)$ & $15(15)$ & $43(43)$ & $12(12)$ \\
\hline Phototransduction & $26(28)$ & $24(24)$ & $45(46)$ & $17(17)$ \\
\hline Proteasome & $35(35)$ & $35(35)$ & $50(50)$ & $45(45)$ \\
\hline \multicolumn{5}{|l|}{ Defence } \\
\hline Endocytosis & $69(69)$ & $66(66)$ & 139 (139) & $75(75)$ \\
\hline Lysosome & $51(52)$ & $53(53)$ & $113(116)$ & $55(59)$ \\
\hline Natural Killer Cell Cytotoxicity & $19(19)$ & $13(13)$ & $36(36)$ & $22(22)$ \\
\hline Phagosome & $38(39)$ & $50(51)$ & $99(100)$ & $44(44)$ \\
\hline Regulation of Autophagy & $12(12)$ & $11(11)$ & $18(18)$ & $14(14)$ \\
\hline Total & 1047 & 980 & 2099 & 1036 \\
\hline (proportion) & $97.9 \%$ & $98.5 \%$ & $96.7 \%$ & $98.5 \%$ \\
\hline
\end{tabular}

* Pathway components unavailable

Biological processes and pathways with the number of pathway proteins with significant matches to BT_transcriptome_v2 contigs in the honeybee, $A$. mellifera, the jewel wasp, N. vitripennis, the fruitfly, D. melanogaster, and the pea aphid, A. pisum. The number of reference proteins are given in brackets.

were mapped uniquely to 33,875 contigs. 7,635 contigs (22\%) received ESTs from all life cycle stages, and these universally expressed genes represented a majority (a mean of $74.5 \%$ ) of the ESTs from each life cycle stage. There were 1,678 (4.9\%) singletons (contigs with a single EST mapping). For 6,341 of the 33,875 contigs expression was detected in only one life cycle stage (Figure 3 ). The larval and pupal stages had the highest proportion of stage-restricted contigs ( $4 \%$ each). The adult stages had few stage-restricted contigs (workers: 3,865 [0.75\% of total worker reads]; male: 4,182 [1.62\% of total]; gyne: 1,449 [0.65\% of total]). The two worker samples were very similar, with $95 \%$ (worker 1) or 97\% (worker 2) of reads mapping to 13,611 shared contigs. Further information regarding the number of unique contigs is provided in Additional file 5.

\section{R-STAT analysis of differential gene expression amongst} life cycle stages and castes

Although our life cycle stage samples are non-replicated, with the exception of the workers $(\mathrm{N}=2)$, to provide a preliminary assessment of potential differential expression across the life cycle stages of the bee, we employed the R-STAT method devised by Stekel et al. [42]. As we did not replicate across life cycle stages, with the exception of the workers, we do not have a full understanding of age or individual variation within the differential expression analysis but operating under the assumption that variation would be minimal between life cycle stages, we examined the following. In total, 2,185 BT_transcriptome_v2 contigs were identified as having high $\mathrm{R}$-values ( $\mathrm{R}$-value $>20$; following the methods by Stekel et al. [42]). The thirty contigs that had the highest R-values amongst all life cycle stages are detailed in Table 2. The ten genes that best distinguish the different life-stages are provided in Additional file 6.

\section{Gene expression within the workers}

The contig with the highest R-value (BTT05460_1; Rvalue $=10,101)$ was identified as alpha-glucosidase, with elevated expression in both workers (Table 2; Additional file 6, Tables S6c and S6d). The workers also had elevated expression of genes involved in flight (sallimus; BTT20899_3); defence (bombolitin; BTT20391_1); 


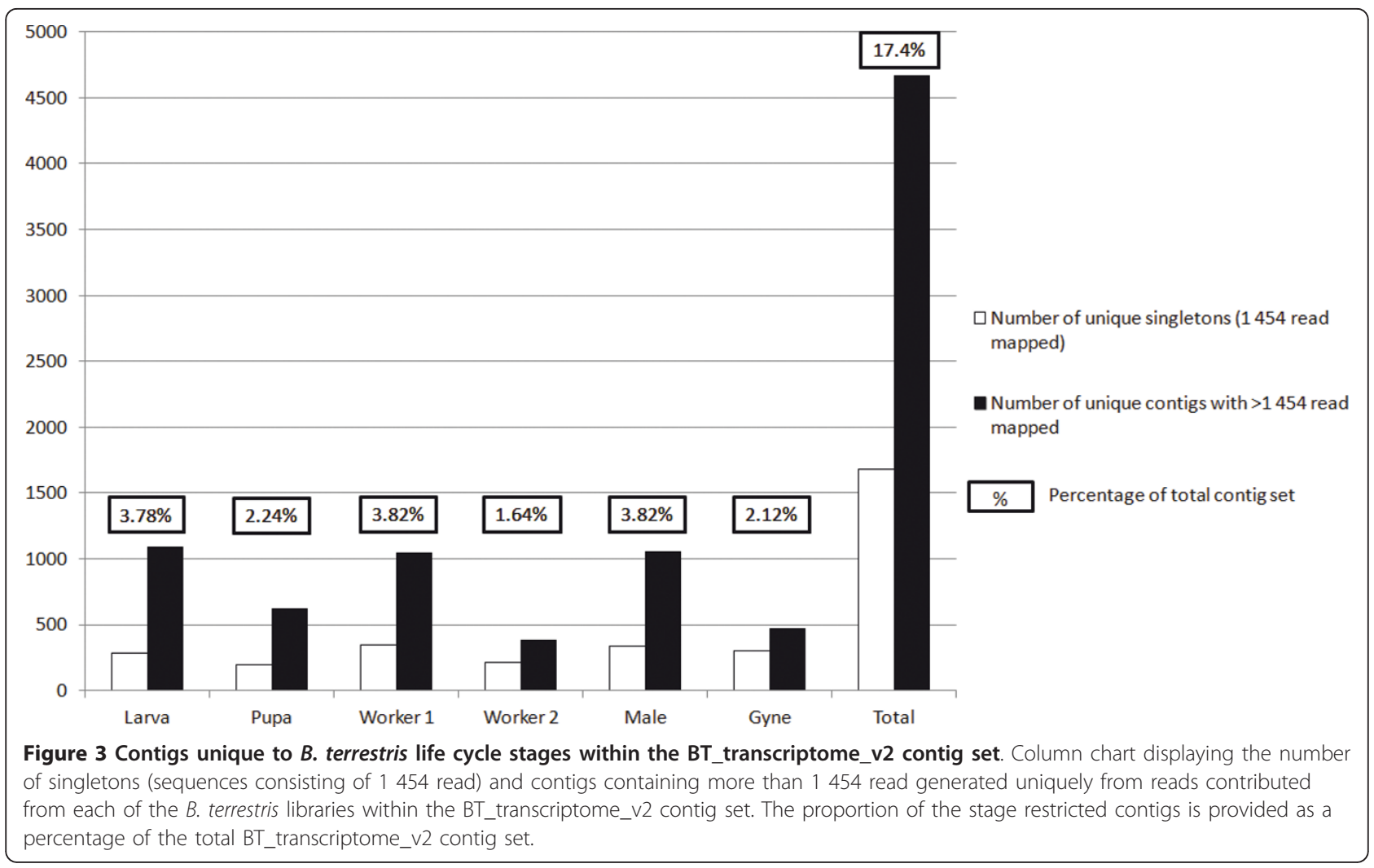

metabolism (two contigs, BTT05294_1 and BTT33135_1, matching cytochrome $\mathrm{P} 450$ proteins); and a protein with domain matches to both haemolymph juvenile hormone binding and mite allergen group-7 (BTT05272_1).

Examination of the ten genes that best distinguish the worker caste (based on genes highly expressed in both worker samples) identified genes involved in metabolism, chitin binding and defence (see Additional file 6: Tables S6c and S6d)). Both workers exhibited high expression of genes involved in metabolism, such as oxidation of organic compounds (three contigs matching three cytochrome P450 proteins (BTT22253_1, BTT24074_1 and BTT22199_1)), and glucose breakdown, (glyceraldehyde-3-phosphate dehydrogenase (BTT00029_1) and glucose oxidase (BTT20590_1)). A lipase (BTT15820_1), involved in the breakdown of lipids essential for periods of high activity, was also highly expressed in the workers. Two contigs (BTT05313_2 and BTT35235_1) matched chitin-binding, peritrophin-like proteins. Two worker-upregulated contigs matched genes implicated in immune defence: allergen-related G12 protein (BTT05276_1) and bombolitin (BTT05263_2). Other contigs highly differentially expressed in workers included diapause-related protein 41 (BTT05480_1; physiological function unknown), and two contigs matching hypothetical proteins from the ant C. floridanus (BTT20743_1) and the honeybee (BTT05577_1). BTT05480_1 and BTT20743_1 have both transmembrane and signal peptide domains suggesting a cell-surface or membrane-bound location.

\section{Gene expression in the gyne}

The top ten differentially expressed genes included elevated expression in the gyne of an amino acid storage protein, hexamerin (BTT05275_2) (see Table 2). Within the ten genes that best distinguish the gyne (see Additional file 6: Table S6f), five contigs matched storage proteins: four hexamerins (BTT05275_2, BTT36615_1, BTT05275_1 and BTT05277_1) and one arylphorin (BTT05260_1). Apart from genes involved in storage, one contig (BTT00028_1) matched acyl-CoA delta-9 desaturase, a protein involved in fatty acid biosynthesis, another a chitin-binding peritrophin (BTT05289_2) and a third crooked, a protein involved in maintenance of tracheal tube structure (BTT18720_1). Two contigs had matches to hypothetical proteins in the ant Brachymyrmex patagonicus (BTT07422_1) and the ant C. floridanus (BTT20597_1). BTT07422_1 was annotated with a predicted signal peptide domain while BTT20597_1 had predicted transmembrane, signal peptide and fibronectin-like 1 domains. 
Table 2 R-STAT analysis for the life cycle stages of $B$. terrestris.

\begin{tabular}{|c|c|c|c|c|c|c|c|c|c|c|c|}
\hline \multirow[t]{2}{*}{ BTT_contig } & \multirow[t]{2}{*}{$\begin{array}{l}\text { Functional } \\
\text { description }\end{array}$} & \multicolumn{2}{|c|}{$\begin{array}{l}\text { Best BLAST Match and GenBank } \\
\text { Accession [species] }\end{array}$} & \multicolumn{8}{|c|}{ Read counts per contig } \\
\hline & & & & Larva $^{a}$ & Pupa $^{\text {b }}$ & Worker ${ }^{c}$ & Worker2 $^{d}$ & Male $^{\mathrm{e}}$ & Gyne $^{f}$ & Total $^{g}$ & $\begin{array}{c}\mathrm{R}- \\
\text { value }\end{array}$ \\
\hline ВТT05460_1 & $\begin{array}{l}\text { Alpha- } \\
\text { glucosidase }\end{array}$ & $\begin{array}{l}\text { Alpha-glucosidase }[B . \\
\text { ignitus] }\end{array}$ & BAI44030.1 & 110 & 6 & 2677 & 6080 & 27 & 3 & 8903 & 10101 \\
\hline BTT05364_1 & Allergen-related & $\begin{array}{l}\text { PREDICTED: similar to } \\
\text { CG4409-PA [A. mellifera] }\end{array}$ & XP_001123230.1 & 5518 & 1 & 0 & 0 & 0 & 1 & 5520 & 8977 \\
\hline BTT03121_2 & $\begin{array}{l}\text { Endocuticle } \\
\text { structural } \\
\text { glycoprotein }\end{array}$ & $\begin{array}{l}\text { Endocuticle structural } \\
\text { glycoprotein SgAbd-1 [C. } \\
\text { floridanus] }\end{array}$ & EFN60841.1 & 5208 & 3 & 0 & 0 & 0 & 0 & 5211 & 8466 \\
\hline BTT05275_2 & Hexamerin & Hexamerin [A. mellifera] & ABR45904.1 & 41 & 45 & 434 & 16 & 55 & 4884 & 5475 & 7619 \\
\hline BTT05433_2 & Hexamerin & $\begin{array}{l}\text { Hexamerin } 110[A . \\
\text { mellifera }]\end{array}$ & ABU92559.1 & 283 & 3384 & 0 & 0 & 0 & 0 & 3667 & 6628 \\
\hline ВТT05434_1 & Peregrin-like & $\begin{array}{l}\text { PREDICTED: similar to } \\
\text { CG1845-PA [A. mellifera] }\end{array}$ & XP_395348.2 & 34 & 2638 & 38 & 21 & 26 & 38 & 2795 & 5011 \\
\hline ВТT05442_1 & Hexamerin & $\begin{array}{l}\text { Hexamerin } 110[\mathrm{~A} . \\
\text { mellifera }]\end{array}$ & NP_001094493.1 & 119 & 2428 & 0 & 0 & 1 & 1 & 2549 & 4834 \\
\hline ВТT05434_2 & $\begin{array}{l}\text { Beta- } \\
\text { ureidopropionase }\end{array}$ & $\begin{array}{l}\text { PREDICTED: similar to } \\
\text { beta-ureidopropionase } \\
\text { isoform } 1 \text { [A. mellifera] }\end{array}$ & XP_392773.2 & 17 & 2489 & 34 & 20 & 32 & 18 & 2610 & 4805 \\
\hline BTT35255_1 & Hexamerin & $\begin{array}{l}\text { Hexamerin } 110[\mathrm{~A} . \\
\text { mellifera] }\end{array}$ & ABU92559.1 & 346 & 2376 & 0 & 0 & 0 & 0 & 2722 & 4551 \\
\hline ВTT20945_1 & Hexamerin & $\begin{array}{l}\text { Hexamerin } 110[\mathrm{~A} . \\
\text { mellifera }]\end{array}$ & BAl82215.1 & 147 & 2304 & 0 & 1 & 0 & 0 & 2452 & 4547 \\
\hline BTT17751_1 & $\begin{array}{l}\text { Short-chain } \\
\text { dehydrogenase/ } \\
\text { Reductase }\end{array}$ & $\begin{array}{l}\text { Short-chain } \\
\text { dehydrogenase/reductase } \\
\text { [A. mellifera] }\end{array}$ & NP_001011620.1 & 0 & 1760 & 0 & 0 & 0 & 0 & 1760 & 3708 \\
\hline ВТT05366_1 & $\begin{array}{l}\text { Endocuticle } \\
\text { structural } \\
\text { glycoprotein }\end{array}$ & $\begin{array}{l}\text { PREDICTED: similar to } \\
\text { CG7658-PA [A. mellifera] }\end{array}$ & XP_001120498.1 & 2153 & 0 & 0 & 0 & 0 & 0 & 2153 & 3489 \\
\hline ВTT23482_1 & Hexamerin & Hexamerin [A. mellifera] & ABR45905.1 & 1 & 1633 & 0 & 1 & 0 & 1 & 1636 & 3423 \\
\hline ВТT35822_1 & Hexamerin & Hexamerin [A. mellifera] & ABR45905.1 & 0 & 1585 & 0 & 0 & 0 & 0 & 1585 & 3337 \\
\hline BTT18911_1 & Hexamerin & $\begin{array}{l}\text { Hexamerin } 70 b[A . \\
\text { mellifera }]\end{array}$ & NP_001011600.1 & 2947 & 15 & 337 & 88 & 99 & 177 & 3663 & 3289 \\
\hline ВТT07410_1 & Vitellogenin & $\begin{array}{l}\text { PREDICTED: hypothetical } \\
\text { protein [A. mellifera] }\end{array}$ & XP_001121939.1 & 0 & 1512 & 0 & 0 & 0 & 1 & 1513 & 3177 \\
\hline BTT05437_1 & Hexamerin & $\begin{array}{l}\text { Hexamerin } 70 \mathrm{c}[\mathrm{A} . \\
\text { mellifera }]\end{array}$ & NP_001092187.1 & 1 & 1496 & 0 & 0 & 0 & 0 & 1497 & 3142 \\
\hline ВТT20899_3 & Sallimus & $\begin{array}{l}\text { PREDICTED: similar to } \\
\text { sallimus CG1915-PC, } \\
\text { isoform C [A. mellifera] }\end{array}$ & XP_001121572.1 & 7 & 0 & 1176 & 1922 & 16 & 305 & 3426 & 2960 \\
\hline ВТT20391_1 & Bomboilitin & Bombolitin [B. ignitus] & ACY09649.1 & 5 & 1 & 1677 & 1691 & 9 & 837 & 4220 & 2944 \\
\hline BTT21092_1 & $\begin{array}{l}\text { Alpha- } \\
\text { glucosidase }\end{array}$ & $\begin{array}{l}\text { Alpha-glucosidase }[B . \\
\text { ignitus] }\end{array}$ & BAI44030.1 & 31 & 1 & 766 & 1685 & 3 & 0 & 2486 & 2822 \\
\hline BTT05276_2 & Allergen-related & $\begin{array}{l}\text { Allergen-related G12 }[\mathrm{H} . \\
\text { saltator] }\end{array}$ & EFN86980.1 & 0 & 0 & 1948 & 819 & 2267 & 458 & 5492 & 2658 \\
\hline BTT38955_1 & $\begin{array}{l}\text { Beta- } \\
\text { ureidopropionase }\end{array}$ & $\begin{array}{l}\text { PREDICTED: similar to } \\
\text { beta-ureidopropionase } \\
\text { isoform } 1 \text { [A. mellifera] }\end{array}$ & XP_392773.2 & 8 & 1190 & 11 & 7 & 13 & 10 & 1239 & 2316 \\
\hline BTT24170_1 & Hymenoptaecin & $\begin{array}{l}\text { Hymenoptaecin }[B . \\
\text { ignitus] }\end{array}$ & ACA04899.1 & 1 & 22 & 0 & 0 & 1345 & 1 & 1369 & 2227 \\
\hline BTT05294_1 & $\begin{array}{l}\text { Cytochrome } \\
\text { P450 }\end{array}$ & $\begin{array}{l}\text { Cytochrome P450 4g15 } \\
\text { [H. saltator] }\end{array}$ & EFN85148.1 & 106 & 29 & 1568 & 2115 & 576 & 762 & 5156 & 2201 \\
\hline BTT20843_1 & $\begin{array}{l}\text { Larval cuticle } \\
\text { protein }\end{array}$ & $\begin{array}{l}\text { PREDICTED: similar to } \\
\text { CG30045-PA [A. mellifera] }\end{array}$ & XP_001120541.1 & 1355 & 0 & 0 & 0 & 0 & 0 & 1355 & 2187 \\
\hline BTT32853_1 & Hexamerin & Hexamerin [A. mellifera] & ABR45905.1 & 1 & 943 & 0 & 0 & 0 & 0 & 944 & 1971 \\
\hline BTT24170_2 & Hymenoptaecin & $\begin{array}{l}\text { Hymenoptaecin }[B . \\
\text { ignitus] }\end{array}$ & ACA04899.1 & 0 & 15 & 1 & 0 & 1171 & 0 & 1187 & 1948 \\
\hline
\end{tabular}


Table 2 R-STAT analysis for the life cycle stages of B. terrestris. (Continued)

\begin{tabular}{|c|c|c|c|c|c|c|c|c|c|c|c|}
\hline ВТT33135_1 & $\begin{array}{l}\text { Cytochrome } \\
\text { P450 }\end{array}$ & $\begin{array}{l}\text { Cytochrome P450 4G11 } \\
\text { [A. mellifera] }\end{array}$ & NP_001035323.1 & 84 & 10 & 1990 & 1472 & 541 & 827 & 4924 & 1944 \\
\hline BTT12993_1 & $\begin{array}{l}\text { Carbonic } \\
\text { anhydrase }\end{array}$ & $\begin{array}{l}\text { Hypothetical protein } \\
\text { SINV_10521 [S. invicta] }\end{array}$ & EFZ18639.1 & 1732 & 8 & 134 & 49 & 252 & 30 & 2205 & 1937 \\
\hline ВТT05272_1 & $\begin{array}{l}\text { Hypothetical } \\
\text { protein }\end{array}$ & $\begin{array}{l}\text { PREDICTED: similar to } \\
\text { CG3246-PA [A. mellifera] }\end{array}$ & XP_395658.3 & 7 & 41 & 1792 & 871 & 1453 & 1399 & 5563 & 1916 \\
\hline
\end{tabular}

$a=$ Total number of larva ESTs $(n=286501) ; b=$ Total number of pupa ESTs $(n=162608) ; c=$ Total number of worker 1 ESTs $(n=318664) ; d=$ Total number of worker2 ESTs ( $n=194969)$; $e=$ Total number of male ESTs $(n=257318) ; f=$ Total number of gyne ESTs $(n=221683) ; g=$ Total number of ESTs $(n=1441743)$. Mapped read contributions from each sequenced life cycle stage were analyzed using R-STAT to identify contigs with potential differential expression. Read counts are provided for each life cycle stage with the corresponding R-value. BT_transcriptome_v2 contigs (BTT_contig) reference, functional description, best $\mathrm{NCBI}$ nonredundant (nr) BLAST match description and GenBank accession are provided for each contig.

\section{Gene expression in the male}

The male sample had a high expression of genes involved in immunity (see Table 2). The male contributed a high proportion of ESTs to a contig similar to the allergen protein G12 (BTT05276_2) and also exhibited high expression of two contigs encoding antimicrobial peptides identified as hymenoptaecins (BTT24170_1 and BTT24170_2). Within the top ten genes that distinguished the male (see Additional file 6, Table S6e) a third hymenoptaecin contig was identified (BTT36277_1). Immunity aside, the male had high expression of genes involved in metabolism (i.e. sentrinlike protease; BTT06274_2) and a serine carboxypeptidase (BTT05501_1), flight (i.e. the muscle protein titin; BTT05775_1) and cuticle formation (i.e. the peritrophin like gene BTT05289_1). Two contigs of unknown function were also overexpressed in the male. One had a predicted fibronectin-like domain (BTT00570_1) while the second contig had transmembrane and signal peptide domains (BTT09205_1).

\section{Gene expression in the larva}

The pre-adult stages accounted for 19 of the top thirty highest $\mathrm{R}$-value annotated contigs ( 6 from the larva and 13 from the pupa). The larva (Table 2) had elevated expression of proteins involved in cuticle formation (BTT03121_2, BTT05366_1, BTT20843_1 and BTT20746_1), and amino acid storage (hexamerin 70b BTT18911_1). A member of the cytochrome P450 superfamily (BTT20966_1) was also highly expressed in the larva. Within the larva we identified elevated expression of additional genes involved in development and cuticle formation (Additional file 6, Table S6a). The enzyme, carbonic anhydrase, which is involved in metabolism, was highly expressed (BTT12993_1). Two functionally unidentified contigs were also overexpressed, one of which (BTT35627_1) had predicted transmembrane and signal peptide domains.

\section{Gene expression within the pupa}

In contrast to the high expression of cuticular and structural proteins in the larva, the pupa had a higher expression of a diversity of amino acid storage proteins (Table 2; Additional file 6, Table S6b). Of the amino acid groups, seven contigs matched hexamerins: four to hexamerin 110 (BTT05433_2, BTT05442_1, BTT35255_1 and BTT20945_1), one to hexamerin 70c (BTT05437_1) and two to an unclassified hexamerin (BTT23482_1 and BTT35822_1). There was a high pupal EST contribution to a contig matching a peregrin-like protein, which has a role in dorsal/ventral axon guidance, an important biological process during transformation from larva to adult. Of the three contigs putatively matching metabolic enzymes, two contigs (BTT05434_2 and BTT38955_1) matched beta-ureidopropionase, an enzyme involved in metabolism of pyrimidine and beta-alanine, while one matched a shortchain dehydrogenase-reductase (BTT17751_1). Vitellogenin, which has a role in lipid transport, was highly expressed in the pupa (BTT07410_1) in comparison to the larva.

\section{Differential expression of immunity-related genes across the $B$. terrestris life cycle}

The development and expression of the immune response in B. terrestris is particularly interesting (see Introduction). We identified $B$. terrestris homologues of the four major A. mellifera immune signalling pathways (Toll, Immune deficiency (ImD), Janus kinase and signal transducer and activator of transcription (JAK-STAT), and JNK immune signalling) in BT_transcriptome_v2 contigs, and analysed these for expression differences among life cycle stages (Figure 4). Of the Toll pathway components, expression was uniform across life cycle stages apart from two signalling components, Tube and Pelle. Neither was expressed in the pupa, while Tube was only detected in the female adult stages (workers and gynes). For the ImD, JNK, and JAK-STAT signalling pathways, two components were not present in BT_transcriptome_v2: the transmembrane receptor Domeless, and the transcription factor for the JNK pathway, JNK MAP Kinase basket. Components of these three pathways were detectably expressed in all stages, but TEPA, DREDD, and TGF- $\beta$ activated kinase 1 (TAK1) were only expressed in workers. Sadd et al. [31] 


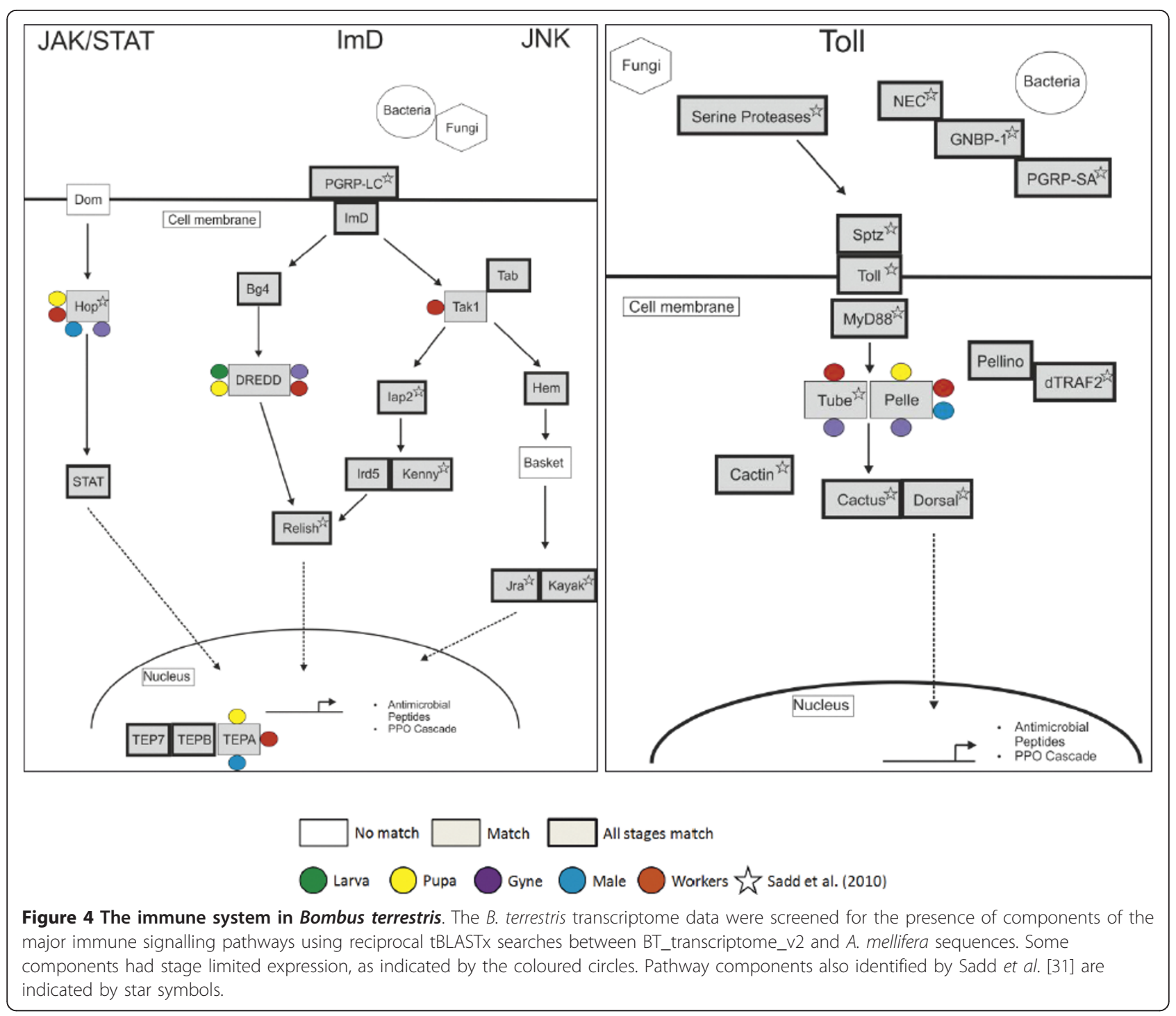

also enumerated pathway component expression in workers, but we identified more complete coverage of expected pathways, including a complete Toll signalling pathway.

Ten immunity-related effector genes were differentially expressed across the sequenced specimens (Table 3). Nine of these were expressed in all life cycle stages (the antimicrobial peptide (AMP) abaecin was absent from the larva). Phenoloxidase subunit A3 (BTT08527_1), which functions in the production of melanin and other polyphenic compounds for both cuticle biosynthesis and immune encapsulation, had highest expression in the pupa. A C-type lectin (BTT07416_1) and a gram-negative binding protein (BTT09196_1), which both have roles in immune detection of bacteria, had elevated expression in the larva, while the gram-positive binding peptidoglycan recognition protein (PGRP) SA was highly expressed in the gyne (BTT21344_1). Transferrin, an iron chelator that impacts on the survival of bacteria within a host, matched 22 contigs with differential expression, of which 20 contigs had high EST contributions in the male while two contigs had high EST contribution from the gyne (BTT35862_1) and the larva (BTT35539_1), respectively (Table 3). The male had elevated expression of the AMPs abaecin, apidaecin, hymenoptaecin and defensin 1 (Table 3: Anti-microbial peptides). Several distinct contigs encoding the Bombus-specific AMP bombolitin (BTT20391_1, BTT34958_1, BTT35608_1 and BTT40712_1), a constituent of venom, showed elevated expression in the female adults, especially the workers.

\section{Differential expression of olfaction genes in $B$. terrestris}

We expected that olfaction would differ among castes and life cycle stages because of their differing needs for, and responses to, social and other cues. We examined 
Table 3 Potential differential expression of immunity-related genes across the life cycle stages of $B$. terrestris.

\begin{tabular}{|c|c|c|c|c|c|c|c|c|c|c|}
\hline \multirow[t]{2}{*}{ BTT_contig } & \multicolumn{2}{|c|}{ Best BLAST Match and GenBank Accession [species] } & \multicolumn{8}{|c|}{ Read counts per contig } \\
\hline & Immune-related Genes & & Larva $^{a}$ & Pupa $^{\text {b }}$ & $\underset{c}{\text { Worker1 }}$ & $\underset{d}{\text { Worker2 }}$ & $\underset{\mathrm{e}}{\text { Male }}$ & Gyne & $\underset{\mathbf{g}}{\text { Total }}$ & $\begin{array}{c}\mathrm{R}- \\
\text { value }\end{array}$ \\
\hline BTT08527_1 & Phenoloxidase subunit A3 [A. mellifera] & NP_001011627.1 & 59 & 78 & 4 & 1 & 3 & 6 & 151 & 123 \\
\hline BTT24384_1 & Transferrin [A. mellifera] & AAO39761.1 & 38 & 58 & 106 & 68 & 530 & 152 & 952 & 395 \\
\hline BTT35190_1 & Transferrin $[A$. mellifera $]$ & AAO39761.1 & 1 & 0 & 7 & 0 & 27 & 4 & 39 & 25 \\
\hline BTT35213_1 & Transferrin [A. mellifera] & AAO39761.1 & 94 & 83 & 199 & 96 & 292 & 238 & 1002 & 95 \\
\hline BTT35261_1 & Transferrin [A. mellifera] & AAO39761.1 & 12 & 9 & 86 & 13 & 148 & 64 & 332 & 113 \\
\hline BTT35441_1 & Transferrin [A. mellifera] & AAO39761.1 & 7 & 3 & 13 & 17 & 49 & 20 & 109 & 29 \\
\hline ВТT35539_1 & Transferrin [A. mellifera] & AAO39761.1 & 34 & 0 & 15 & 30 & 4 & 17 & 100 & 28 \\
\hline BТT35592_1 & Transferrin [A. mellifera] & AAO39761.1 & 9 & 0 & 13 & 3 & 74 & 20 & 119 & 66 \\
\hline ВТT35613_1 & Transferrin [A. mellifera] & AAO39761.1 & 9 & 6 & 28 & 16 & 64 & 34 & 157 & 35 \\
\hline BTT35644_1 & Transferrin [A. mellifera] & AAO39761.1 & 10 & 14 & 55 & 9 & 117 & 53 & 258 & 82 \\
\hline BTT35679_1 & Transferrin [A. mellifera] & AAO39761.1 & 0 & 0 & 60 & 3 & 119 & 37 & 219 & 134 \\
\hline ВТT35708_1 & Transferrin [A. mellifera] & AAO39761.1 & 0 & 0 & 8 & 0 & 24 & 3 & 35 & 23 \\
\hline BТT35750_1 & Transferrin [A. mellifera] & AAO39761.1 & 4 & 5 & 35 & 6 & 55 & 27 & 132 & 39 \\
\hline ВТT35862_1 & Transferrin [A. mellifera] & AAO39761.1 & 0 & 0 & 15 & 0 & 0 & 150 & 165 & 236 \\
\hline ВТT35895_1 & Transferrin [A. mellifera] & AAO39761.1 & 0 & 0 & 10 & 0 & 31 & 10 & 51 & 31 \\
\hline ВТT35931_1 & Transferrin [A. mellifera] & AAO39761.1 & 13 & 0 & 18 & 1 & 35 & 17 & 84 & 24 \\
\hline ВТT35947_1 & Transferrin [A. mellifera] & AAO39761.1 & 0 & 6 & 8 & 1 & 37 & 8 & 60 & 33 \\
\hline BTT07416_1 & $\begin{array}{l}\text { PREDICTED: similar to CG3244-PA, partial [A. } \\
\text { mellifera] }\end{array}$ & XP_624536.1 & 375 & 9 & 6 & 4 & 7 & 38 & 439 & 463 \\
\hline BTT21344_1 & $\begin{array}{l}\text { Peptidoglycan-recognition protein SA [A. } \\
\text { mellifera] }\end{array}$ & NP_001157187.1 & 56 & 159 & 116 & 22 & 72 & 169 & 594 & 121 \\
\hline \multirow[t]{2}{*}{ ВТT09196_1 } & $\begin{array}{l}\text { Gram-negative bacteria-binding protein } 1-2 \\
\text { [A. mellifera] }\end{array}$ & NP_001157186.1 & 141 & 10 & 90 & 57 & 86 & 26 & 410 & 56 \\
\hline & Anti-microbial Peptides & & & & & & & & & \\
\hline ВТT39615_1 & Abaecin [A. mellifera] & AAA67442.1 & 0 & 0 & 0 & 0 & 24 & 0 & 24 & 30 \\
\hline ВТT08491_1 & Abaecin [A. mellifera] & AAA67442.1 & 0 & 0 & 0 & 0 & 45 & 0 & 45 & 64 \\
\hline BTT20802_1 & Abaecin [A. mellifera] & AAA67442.1 & 0 & 5 & 0 & 0 & 122 & 6 & 133 & 174 \\
\hline BTT37089_1 & Abaecin [A. mellifera] & AAA67442.1 & 0 & 0 & 2 & 1 & 57 & 6 & 66 & 71 \\
\hline BTT38306_1 & Abaecin [A. mellifera] & AAA67442.1 & 0 & 0 & 1 & 1 & 31 & 0 & 33 & 38 \\
\hline BTT05666_1 & Apidaecin [A. mellifera] & CAA51168.1 & 3 & 7 & 1 & 3 & 55 & 3 & 72 & 59 \\
\hline BTT20828_1 & Apidaecin [A. mellifera] & CAA51168.1 & 9 & 33 & 7 & 9 & 128 & 16 & 202 & 123 \\
\hline BTT35749_1 & Apidaecin [A. mellifera] & CAA51168.1 & 2 & 2 & 14 & 24 & 8 & 29 & 79 & 27 \\
\hline BTT38204_1 & Apidaecin [A. mellifera] & CAA51168.1 & 0 & 4 & 1 & 2 & 25 & 0 & 32 & 27 \\
\hline BTT41196_1 & Apidaecin [A. mellifera] & CAA51168.1 & 0 & 11 & 2 & 3 & 137 & 7 & 160 & 180 \\
\hline BTT41985_1 & Apidaecin [A. mellifera] & CAA51168.1 & 4 & 13 & 3 & 4 & 81 & 2 & 107 & 90 \\
\hline BTT20391_1 & Bombolitin [B. ignitus] & ACY09649.1 & 5 & 1 & 1677 & 1691 & 9 & 837 & 4220 & 2944 \\
\hline ВТT34958_1 & Bombolitin [B. ignitus] & ACY09649.1 & 1 & 0 & 49 & 18 & 1 & 15 & 84 & 46 \\
\hline ВТT35608_1 & Bombolitin [B. ignitus] & ACY09649.1 & 0 & 0 & 201 & 98 & 0 & 180 & 479 & 317 \\
\hline BTT40712_1 & Bombolitin [B. ignitus] & ACY09649.1 & 0 & 0 & 341 & 148 & 1 & 133 & 623 & 422 \\
\hline BTT10405_1 & Defensin $1[B$. terrestris $]$ & ADB29129.1 & 2 & 2 & 0 & 0 & 85 & 0 & 89 & 122 \\
\hline ВТT31016_1 & Defensin $1[$ B. terrestris] & ADB29129.1 & 0 & 0 & 0 & 0 & 179 & 0 & 179 & 289 \\
\hline BTT41393_1 & Defensin 1 [B. terrestris] & ADB29129.1 & 3 & 0 & 3 & 3 & 25 & 1 & 35 & 21 \\
\hline BTT42034_1 & Defensin $1[B$. terrestris $]$ & ADB29129.1 & 0 & 2 & 3 & 3 & 47 & 0 & 55 & 56 \\
\hline BTT24170_1 & Hymenoptaecin [A. mellifera] & AAA67444.1 & 1 & 22 & 0 & 0 & 1345 & 1 & 1369 & 2226 \\
\hline BTT24170_2 & Hymenoptaecin [A. mellifera] & AAA67444.1 & 0 & 15 & 1 & 0 & 1171 & 0 & 1187 & 1948 \\
\hline ВТT36277_1 & Hymenoptaecin [A. mellifera] & AAA67444.1 & 0 & 8 & 3 & 0 & 882 & 0 & 893 & 1460 \\
\hline BTT37570_1 & Hymenoptaecin [A. mellifera] & AAA67444.1 & 0 & 0 & 0 & 0 & 41 & 0 & 41 & 57 \\
\hline BTT41217_1 & Hymenoptaecin [A. mellifera] & AAA67444.1 & 0 & 0 & 0 & 0 & 70 & 0 & 70 & 105 \\
\hline BTT18071_1 & Hymenoptaecin [A. mellifera] & AAA67444.1 & 0 & 1 & 0 & 0 & 27 & 0 & 28 & 34 \\
\hline BTT35620_1 & Hymenoptaecin [A. mellifera] & AAA67444.1 & 0 & 0 & 40 & 10 & 13 & 15 & 78 & 30 \\
\hline
\end{tabular}


Table 3 Potential differential expression of immunity-related genes across the life cycle stages of $B$. terrestris. (Continued)

\begin{tabular}{|c|c|c|c|c|c|c|c|c|c|c|}
\hline BTT36443_1 & Hymenoptaecin [A. mellifera] & AAA67444.1 & 12 & 34 & 17 & 10 & 47 & 38 & 158 & 29 \\
\hline ВТT37051_1 & Hymenoptaecin [A. mellifera] & AAA67444.1 & 0 & 0 & 0 & 0 & 183 & 0 & 183 & 296 \\
\hline BTT41185_1 & Hymenoptaecin [A. mellifera] & AAA67444.1 & 0 & 6 & 0 & 0 & 64 & 0 & 70 & 90 \\
\hline BTT42611_1 & Hymenoptaecin [A. mellifera] & AAA67444.1 & 0 & 0 & 0 & 0 & 20 & 0 & 20 & 24 \\
\hline
\end{tabular}

$a=$ Total number of larva ESTs $(n=286501) ; b=$ Total number of pupa ESTs $(n=162608) ; c=$ Total number of worker1 ESTs $(n=318664) ; d=$ Total number of worker2 ESTs ( $n=194969)$; $e=$ Total number of male ESTs $(n=257318) ; f=$ Total number of gyne ESTs $(n=221683) ; g=$ Total number of ESTs $(n=1441743)$. Immunity-related genes were identified in BT_transcriptome_v2 and are shown with read counts for each life cycle stage. The highest amount of ESTs per contig is highlighted in bold.

the presence and differential expression of olfactionrelated genes, namely the odorant-binding proteins (OBPs) and the chemosensory proteins (CSPs) (Table 4). Both larva and pupa had low expression of OBPs, with the exception of high expression of OBP13 in the pupa (Table 4 and Figure 5). In addition, OBP2 (BTT27418_1, BTT42039_1) OBP3 (BTT35749_1) and OBP4 (BTT41749_1), OBP13 (BTT26653_1) were expressed in the pupa while OBP3 and OBP13 were only expressed in the larva (Figure 5). Four CSPs, namely CSP2 (BTT00638_1), CSP3 (BTT19102_1), CSP4 (BTT17558_1, BTT26377_1) and CSP6 (BTT35682_1), were expressed in the larva with particularly high expression of CSP3 (BTT19102_1) and heightened expression of CSP4 in comparison to the pupa (BTT34298_1). The pupa only expressed three CSPs (CSP2, CSP3 and CSP4).
The adult stages had a heightened expression of OBP2 and OBP3 in comparison to the larval and pupal stages (Table 4). Contigs identified as OBP2 (BTT08587_1; BTT11797_1, BTT20806_1 and BTT40878_1) and OBP3 (BTT05623_1 and BTT20849_1) had elevated expression in the adult stages in comparison to the larva, and were not expressed in pupa. OBP13-like proteins were highly expressed in the pupa (BTT20296_1) and the male (BTT16540_1; BTT26653_1). In addition, OBP1 and OBP6 were detected in all adult stages but in neither the larva nor the pupa. OBP11 was only expressed in the sexuals (male and gyne) while OBP9 was only expressed in the male. Four CSPs expressed in the larva were expressed in the adult stages. There was an elevated expression of CSP4 in the female adults in comparison to the male.

Table 4 Potential differential expression of olfaction-related genes in the life cycle stages of $B$. terrestris.

\begin{tabular}{|c|c|c|c|c|c|c|c|c|c|c|}
\hline \multirow{3}{*}{$\begin{array}{l}\text { BTT_contig } \\
\text { BTT08587_1 }\end{array}$} & \multicolumn{2}{|c|}{ Best BLAST Match and GenBank Accession [species] } & \multicolumn{8}{|c|}{ Read counts per contig } \\
\hline & \multicolumn{2}{|c|}{ Odorant binding proteins } & \multirow{2}{*}{$\frac{\operatorname{Larva}^{a}}{0}$} & \multirow{2}{*}{$\frac{\text { Pupa }^{\text {b }}}{0}$} & \multirow{2}{*}{$\begin{array}{c}{\text { Worker }{ }^{c}}^{c} \\
129\end{array}$} & \multirow{2}{*}{$\frac{\text { Worker2 }^{\mathrm{d}}}{83}$} & \multirow{2}{*}{$\frac{\text { Male }^{\mathbf{e}}}{97}$} & \multirow{2}{*}{$\begin{array}{c}\text { Gyne }^{f} \\
172\end{array}$} & \multirow{2}{*}{$\begin{array}{c}\text { Total }^{\mathbf{9}} \\
481\end{array}$} & \multirow{2}{*}{$\frac{\text { R-value }}{193}$} \\
\hline & OBP 2 [A. mellifera] & NP_001011591.1 & & & & & & & & \\
\hline BTT11797_1 & OBP 2 [A. mellifera] & NP_001011591.1 & 0 & 0 & 19 & 14 & 40 & 11 & 84 & 35 \\
\hline BTT20806_1 & OBP 2 [A. mellifera] & NP_001011591.1 & 1 & 0 & 63 & 109 & 86 & 61 & 320 & 129 \\
\hline BTT40878_1 & OBP 2 [A. mellifera] & NP_001011591.1 & 0 & 0 & 11 & 3 & 19 & 18 & 51 & 20 \\
\hline BTT05623_1 & OBP 3 [A. mellifera] & NP_001035311.1 & 0 & 0 & 32 & 11 & 110 & 77 & 230 & 134 \\
\hline BTT20849_1 & OBP 3 [A. mellifera] & NP_001035311.1 & 0 & 0 & 56 & 32 & 46 & 100 & 234 & 103 \\
\hline BTT16540_1 & OBP 13[A. mellifera] & NP_001035314.1 & 0 & 0 & 0 & 0 & 31 & 0 & 31 & 41 \\
\hline BTT20296_1 & OBP13 [A. mellifera] & ABD92645.1 & 93 & 776 & 116 & 22 & 22 & 91 & 1120 & 1045 \\
\hline BTT26653_1 & OBP13 [A. mellifera] & ABD92645.1 & 0 & 1 & 0 & 0 & 47 & 0 & 48 & 66 \\
\hline \multicolumn{11}{|c|}{ Chemosensory Proteins } \\
\hline BTT00638_1 & CSP $2[$ A. mellifera $]$ & NP_001071278.1 & 8 & 30 & 7 & 6 & 19 & 5 & 75 & 23 \\
\hline BTT19102_1 & CSP 3 precursor [A. mellifera] & NP_001011583.1 & 467 & 16 & 56 & 19 & 64 & 126 & 748 & 385 \\
\hline BTT17558_1 & CSP $4[$ A. mellifera $]$ & NP_001071282.1 & 34 & 20 & 53 & 115 & 66 & 31 & 319 & 57 \\
\hline BTT20849_1 & CSP 4 [A. mellifera] & NP_001071282.1 & 0 & 0 & 56 & 32 & 46 & 100 & 234 & 103 \\
\hline BTT26377_1 & CSP 4 [A. mellifera] & NP_001071282.1 & 15 & 15 & 68 & 69 & 67 & 43 & 277 & 38 \\
\hline BTT34298_1 & CSP 4 [A. mellifera] & NP_001071282.1 & 45 & 0 & 3 & 3 & 8 & 4 & 63 & 39 \\
\hline BTT39167_1 & CSP 4 [A. mellifera] & NP_001071282.1 & 11 & 8 & 52 & 39 & 37 & 33 & 180 & 22 \\
\hline ВТT35682_1 & CSP 6 [A. mellifera] & NP_001071287.1 & 1 & 0 & 37 & 16 & 99 & 25 & 178 & 92 \\
\hline
\end{tabular}

$a=$ Total number of larva ESTs $(n=286501) ; b=$ Total number of pupa ESTs $(n=162608) ; c=$ Total number of worker1 ESTs $(n=318664) ; d=$ Total number of worker2 ESTs ( $n=194969)$; $e=$ Total number of male ESTs $(n=257318) ; f=$ Total number of gyne ESTs $(n=221683) ; g=$ Total number of ESTs ( $n=1441743$ ). Potential odorant-binding proteins and chemosensory proteins in the BT_transcriptome_v2 contigs are shown, with read counts for each of the life cycle stages. The highest amount of ESTs per contig are highlighted in bold. 


\begin{tabular}{|c|c|c|c|c|c|c|c|c|c|c|c|c|}
\hline \multirow[b]{3}{*}{ Larva } & \multicolumn{8}{|c|}{ Odorant Binding Proteins } & \multicolumn{4}{|c|}{ Chemosensory Proteins } \\
\hline & OBP1 & OBP2 & OBP3 & OBP4 & OBP6 & OBP9 & OBP11 & OBP13 & CSP2 & CSP3 & CSP4 & CSP6 \\
\hline & & & & & & & & & & & & \\
\hline \multicolumn{13}{|l|}{ Pupa } \\
\hline \multicolumn{13}{|l|}{ Worker 1} \\
\hline \multicolumn{13}{|l|}{ Worker 2} \\
\hline \multicolumn{13}{|l|}{ Male } \\
\hline \multicolumn{13}{|l|}{ Gyne } \\
\hline & & & & Absent: $\mathrm{N}$ & EST cont & bution to & natching $\mathrm{c}$ & & & & & \\
\hline & & & & Low expre & ion: $1-1$ & ESTs co & ributed to & atching $\mathrm{cc}$ & & & & \\
\hline & & & & High expr & sion: 10 & 00 ESTs & ontributec & matchin & ontigs & & & \\
\hline & & & & Very high & pressior & $200 \mathrm{EST}$ & contribut & to matchi & contigs & & & \\
\hline
\end{tabular}

\section{Discussion}

We have used Roche 454 deep sequencing to define and compare the transcriptomes expressed by life cycle stages and castes of $B$. terrestris. Together, these data form a comprehensive gene catalogue for this ecologically and economically important species. The de novo assembly had high contiguity, with a mean contig length of 1,102 bases. The $\mathrm{G}+\mathrm{C}$ content for the contigs was $36 \%$, which is similar to the worker-sequencing results of Sadd et al. [31]. The majority of contigs (approximately $58 \%$ ) had significant BLAST matches to previously described proteins. The remaining $42 \%$ may derive from untranslated regions of unassembled mRNAs, noncoding RNAs or transcriptional noise (retained introns and similar), or, more interestingly, from $B$. terrestris genes that are either novel or have diverged significantly from any sequenced relatives. Comparison of the $B$. terrestris transcriptome against the emerging $B$. terrestris genome sequence identified matches for $95.9 \%$ of the contigs, and we expect that our data will be of utility in annotation efforts for this genome (which is currently being carried out by the Bombus sequencing consortium; K. Worley, P. SchmidHempel, G. Robinson, pers.comm.). Separate sequencing of individual life stages permitted the identification of potentially differentially expressed genes across the life cycle stages using R-STAT, and identified potentially important candidate genes underpinning stage- and caste-specific phenotypes. While we drew samples from two natal colonies, comparison of expression between the workers from the two colonies demonstrated significant similarity, justifying an overall comparison of preadult stages and adult stages.

We used R-STAT analyses to identify a list of potentially differentially expressed contigs, in order to provide direction for future studies examining gene expression within or across life cycle stages of $B$. terrestris.
However, some data already exist in support of this approach. In a previous study by Pereboom et al. [11], northern blot analyses examined expression differences between whole bodied larvae and adults (queen and worker stages) and identified three genes (endocuticle structural glycoprotein; hexamerin $70 \mathrm{~b}$; and $60 \mathrm{~S}$ acidic ribosomal protein P2) that were more highly expressed in larvae than in adults, where expression was absent. These genes match contigs generated from our transcriptomic R-STAT analyses that show the same larvaadult expression pattern, providing independent support for the biological validity of the results discussed below.

\section{Differential gene expression linked to developmental processes}

We identified a number of key differences in genes implicated in developmental processes across the different life stages. For example, the larval data showed high expression of genes involved in cuticle biogenesis. As the larval stage represents a period of feeding and growth, undergoing four developmental moults over a fourteen day period, this upregulation of cuticular proteins and endocuticle structural glycoproteins is expected. Other contigs identified in the transcriptome with similar expression profiles are thus likely candidates for genes with similar stage-specific roles. For example, a short-chain dehydrogenase/reductase (SDR) had elevated expression in the pupa. SDRs function in hormone and steroid metabolism [43], and in social insects, may be involved in stage and caste differentiation, for example through binding juvenile hormone. An SDR was demonstrated to be differentially expressed at the mRNA level in the ovaries in developing larvae of honeybee workers and queens, and SDR gene expression was higher in the ovaries of worker larvae in comparison to queen larvae resulting in possible inhibition of ovary development [44]. The likely co-orthologues 
found in our study of the A. mellifera SDR analysed by Guidugli et al. [44] were derived solely from pupal reads, while Guidugli et al. [44] reported expression being highest in final stage honeybee larvae. Thus, we propose that these SDRs are candidate genes for further investigation into their roles in bumblebee caste determination.

\section{Amino-acid storage protein expression across the bumblebee life cycle}

Hexamerins are amino acid storage proteins, related to tyrosinases [45], used during non-feeding periods of adult development to provide amino acids and energy [46]. Hexamerins also have roles in the binding of juvenile hormone during insect development, impacting on growth regulation within the larval stage [47-49]. A number of studies [50-53] have demonstrated differential expression of hexamerin proteins (hexamerin 70a, hexamerin 70b, hexamerin 70c and hexamerin 110) at different stages of development amongst the sexes and castes in the honeybee. In B. terrestris, the pupal sample had elevated expression of hexamerin 110-like genes and a hexamerin 70 homologue, while the larva had elevated expression of distinct hexamerin 70-like genes, and the gyne elevated expression of four additional hexamerin 70-like genes. Thus while only four hexamerinencoding genes were identified in A. mellifera [53], we have identified potentially ten in $B$. terrestris that show differential expression between life cycle stages and castes, suggesting that these proteins may play complex roles in bumblebee development.

Why would gynes express high levels of amino acid storage proteins? Honeybee virgin queens have a higher expression of hexamerins in comparison to workers, with the hexamerins functioning in gonad development [53], whilst in the wasp, P. metricus, developing gynes have higher quantities of Hex 1 than workers [54]. Studies on hexamerins in other social insects, such as ants and termites, have identified a correlation between depletion of hexamerins within queens and colony formation $[55,56]$. Therefore, this potentially high expression of hexamerins would be important for a $B$. terrestris gyne from a colony formation viewpoint. However, as $B$. terrestris queens undergo a prolonged hibernation after mating, amino acid storage proteins may be important for maintaining functional operation of crucial biological processes during a period of intense stress. As hibernation is a key stage in the life cycle of bumblebees, many species of which are in drastic worldwide decline [57], our results provide direction for future work to analyse the mechanisms behind successful hibernation in these insects.

\section{Genes involved in adult behaviour and physiology}

Workers had elevated expression of enzymes, such as alpha-glucosidase and a muscle-specific lipase, that would be important for worker task completion. Alphaglucosidase is involved in carbohydrate metabolism and utilised by foraging honeybees to metabolise nectar into fructose and glucose [58], while the muscle lipase is important for breaking down lipids during periods of high activity [59]. Interestingly, in our study both enzymes were expressed at an early stage in the adult workers' life (only 72 hours old), in contrast to their temporal pattern of expression in A. mellifera workers. Honeybee workers demonstrate a strict temporal polyethism, where younger workers perform nursing duties while older workers forage [60], and it is these foraging workers that exhibit higher expression of these enzymes. In comparison, there is no strong age-dependent division of labour within bumblebees [61]. Alloethism within bumblebee workers has been correlated with size, with studies identifying larger workers performing foraging tasks while smaller workers perform in-nest functions, although this division of labour can change depending on the requirements of the colony [30]. Thus future work might focus on size- and age-related differences in gene expression between $B$. terrestris workers in relation to their subroles within the colony.

Males are underrepresented in genomic studies in social insects as the emphasis has been almost exclusively on females. In the current study, the male had elevated expression of titin, a muscle protein, expressed in the insect flight muscles [62]. As the male bumblebee requires flight for foraging, patrolling and indeed mating, high expression of flight-specific muscles would be required. In relation to behaviour, the male had a high expression of a neuroparsin, queen brain selective protein 1 , which has been suggested to function in caste determination during honeybee development through manipulation of the insect insulin-like pathway [63]. However, neuroparsins have been suggested to play roles in a wide variety of functions, including reproduction [64]. Therefore, a neuroparsin-like protein in the bumblebee may have male-specific expression in relation to its behaviour or physiology. The male had elevated expression of several genes that matched hypothetical or otherwise unannotated proteins in the genomes of $A$. mellifera, C. floridanus and S. invicta. It is particularly interesting that the male received so many fully unannotated protein matches $(\mathrm{n}=851$ contigs). This may suggest possible novel expression associates with malespecific behaviour and/or physiology. Thus, these data offer valuable insights into the mechanistic basis of male biology in social insects, which has largely been ignored by previous studies (see references above). 


\section{The immune response in males}

Even in the absence of overt infectious challenge, the background level of immune defence is likely to be regulated through the bumblebee life cycle. We did not explicitly challenge the sampled bees with pathogens, but also did not keep them in germ-free environments (pre-adults in their natal colony, adults in nurseries), and thus we expect a background level of immune activation. $B$. terrestris queens are monandrous, mating only once [65], while males can mate up to eight times [66]. In addition, $B$. terrestris exhibits highly male-biased sex ratios [67]. Together, this suggests high levels of competition among the males to mate with gynes. Consequently, males should invest in reproductive fitness, which has been demonstrated in other insect species to trade-off against immunity (e.g. Anopheles gambiae [68]). We identified genes involved in pathogen recognition, the transduction of recognition signals, and immune effectors, and analysed their patterns of expression for data to support this hypothesis. Surprisingly, in contrast to our expectations based on life-history theory, the male had elevated expression (compared to other stages) of AMPs involved in the removal of infectious agents as part of the immune system [69-72], including hymenoptaecin, defensin, abaecin and apidaecin. This is the first account of an apidaecin-type protein being expressed in B. terrestris. Wilfert et al. [73] found no trade-offs between either branch of the immune system (prophenoloxidase (PPO) and AMP) and reproductive investment, but rather a positive correlation between AMPs and reproduction. Wilfert et al. [73] suggest the basis for the positive correlation may be because males pass on AMPs with their sperm to mates during copulation. However, the male in our study was very young and we sampled the whole body rather than just reproductive tissue, making the mating-gift hypothesis less convincing. Unlike the majority of social insect males, bumblebee males do not remain within the colony postemergence from the pupal case. Bumblebee males forage for themselves and spend the majority of their time patrolling scent-marked trails [26]. Bumblebee males can survive outside the colony for up to 60 days (Brown, M.J.F., unpublished data). Thus males cannot take advantage of proposed colony-level social immunity [74] and a primed immune system might be an adaptation to life outside the colony. Thus, our results suggest that the life-history differences between males (effectively solitary) and females (colonial) may impose divergent selection on expression of immune system genes in social insects.

\section{Olfaction in the bumblebee}

Olfaction and the ability to discriminate a number of volatiles is of immense importance to insects in general, and social insects in particular. They must recognise nest-mates, discriminate and control subordinates, select mates, and discriminate between a wide range of plants for food collection. Here we discuss two classes of olfaction genes, the odorant binding proteins (OBPs) and the chemosensory proteins (CSPs).

In the honeybee genome, 21 OBP genes have been identified and examined for patterns of expression [75]. Within our transcriptome dataset, we found significant matches for eight A. mellifera OBPs (OBP1, OBP2, OBP3, OBP4, OBP6, OBP9, OBP11 and OBP13). This enables us to compare their expression in bumblebees to that of their homologues in honeybees. In the honeybee, OBP1, OBP4, OBP6 and OBP11 are expressed exclusively in the antennae of adults [75] and OBP11 was identified as having gender-specific expression (absent from honeybee drones), suggesting a role in female recognition of mates [75]. We found low expression of a $B$. terrestris orthologue of A. mellifera OBP1 (formerly known as antennal specific protein 1), which is involved in binding of queen pheromone in honeybees [76]. In honeybees, OBP1 is expressed in workers' and drones' antennae after approximately 14 days post-emergence [76]. As we sampled our bees before this late timepoint, level of expression of the OBP1 homologue may simply be due to developmental staging. OBP6 was expressed in all the adult bumblebee stages, but not the larva and pupa, matching expression patterns in the honeybee. In contrast, OBP11 was expressed in only the male and gyne. Consequently, OBP11 in the bumblebee may have a role in mate recognition within both sexes, as opposed to the putative female-specific role in honeybees.

OBP2 had elevated expression in all adult stages of $B$. terrestris. In honeybees, OBP2 is expressed specifically in the antenna with weak expression in the legs and head, possibly from chemosensory sensilla in these body parts [75]. In contrast, OBP3 is ubiquitously expressed in all adult body parts of the honeybee with the exception of the antennae [75]. In B. terrestris, OBP3 was highly expressed in all the bumblebee adult stages, with higher expression in the gyne than in the worker, but was absent from the larva and pupa, which again matches honeybee expression patterns. OBP9 is only expressed in the ovaries and eggs of the queen in honeybees [75] but in B. terrestris the male was the only sample to show expression of OBP9. Lastly, OBP13 was highly expressed in the $B$. terrestris pupa and male, but Forêt and Maleszka [75] identified expression of A. mellifera OBP13 in old larvae, with expression continued throughout the pupal stage. It appears that expression of these odorant binding proteins has been conserved in some cases, whilst diverging in others, presumably in response to taxon-specific selection processes. 
We identified four putative CSPs (homologues of CSP2, CSP3, CSP4 and CSP6 in A. mellifera) in the B. terrestris transcriptome. B. terrestris CSP3 and CSP4 had elevated expression in the larva, matching the results of Forêt et al. [77] who found A. mellifera CSP3 to exhibit highest expression in the larva before pupal and imaginal moults. While Briand et al. [78] proposed that CSP3 had a role in brood pheromone recognition, Forêt et al. [77] proposed that CSP3 may play a role in cuticle maturation. In A. mellifera, CSP4 expression was restricted to olfactory tissues in adult, but not pre-adult stages [77]. In contrast, while we detected CSP4 expression in adult $B$. terrestris, the highest expression was in the larva. In honeybees, CSP2 was expressed at low levels throughout the life cycle stages while CSP6 was expressed throughout the larva, pupa and adult stages, with elevated tissue-specific expression in queen ovaries and eggs [77]. The expression of CSP2 and CSP6 across the bumblebee life stages is consistent with that of the honeybee. We were surprised not to have detected a homologue of $A$. mellifera CSP1, which is expressed ubiquitously across honeybee life cycle stages. Finally, $A$. mellifera CSP 5 is expressed only by mature queen honeybees in eggs and ovaries, stages we did not sample in B. terrestris.

Overall, the examination of olfaction-related genes in $B$. terrestris reveals both similarities and also striking differences from their expression in A. mellifera. We expect that these divergences reflect the different social structuring of bumblebee compared to honeybee colonies, and in particular the differing roles and strategies adopted by different castes in these two species. Again, our results provide indications of fruitful lines of future research into how patterns of gene expression relate to the evolution of primitive (bumblebees) and advanced (honeybees) sociality.

\section{Conclusions}

The role of differential gene expression in polyphenism within groups is only beginning to be understood, e.g. [4,11-15,79]. As a step towards understanding genes influential in the expression of specific phenotypes throughout an individual's life cycle stage, we performed a transcriptome-wide analysis of individual specimens of the pre-adult stages, castes and sexes of the bumblebee to improve our knowledge of differential gene expression across the life history of this ecologically and agriculturally important pollinator. We have identified sets of genes that are candidates for regulators and effectors of different phenotypes, and revealed the differing physiological states of each morph. These candidate genes will prove important for future genomic and proteomic studies on $B$. terrestris.
The $B$. terrestris genome is being sequenced, and a BAC library and a number of genetic linkage maps have been constructed to provide greater genomic resources for this important insect [73,80-82]. Our study contributes to this global effort through 504 Mb of Roche 454 transcriptomic data for $B$. terrestris. We provide a central, web-based transcriptomics resource for $B$. terrestris [83], that facilitates user querying of sequences and functional annotations. These data are now a bridgehead into deeper, molecular analyses of the physiological, genetic and evolutionary bases of polyphenism, and the further development of the bumblebee as a model social insect.

\section{Methods}

\section{Animals}

B. terrestris colonies (Koppert, Netherlands) were maintained at $27 \pm 1^{\circ} \mathrm{C}(45-50 \% \mathrm{RH})$ under red light. Pollen and sugar water (ApiInvert ${ }^{\circledR}$ ) were supplied to the colonies ad libitum. Two colonies were chosen where the founding queen was present, only worker callows were emerging from hatching pupal cases and sexual offspring, i.e., males and gynes, were absent. From one colony, individual specimens of worker life stages (larva, pupa and worker, known hereafter as worker 2) were collected. Adult stages (male, gyne and worker, known hereafter as worker 1) were similarly collected from the second colony. Workers were collected from both colonies to provide a comparison of gene expression across the colonies for the worker phenotype. In total, six individuals (one worker larva, one worker pupa, one male, one gyne and two worker adults) were collected for transcriptomic analyses. The larva and pupa were maintained in their natal colony and monitored daily using photography. At seven days of development, the larva (third instar) and pupa were removed, snap frozen in liquid nitrogen and stored at $-80^{\circ} \mathrm{C}$. Upon emergence, adults were removed to a nursery, which housed three distinguishable older workers, each with clipped wings, a brood clump, pollen and sugar water (providing both a normal social environment to stimulate normal gene expression in the newly emerged adults and a setting that was simple to monitor). The presence of older workers within the nursery would suppress ovarian development and subsequent egg laying within subordinate younger adults. Adults matured in the nursery for three days. Adults were then sacrificed by snap freezing in liquid nitrogen and stored at $-80^{\circ} \mathrm{C}$.

\section{RNA Extraction, CDNA synthesis and EST sequencing}

Total RNA was isolated from the whole bodies of specimens using TRIzol Reagent (Invitrogen, UK) according to the manufacturer's instructions. Each specimen was 
ground using a high performance disperser ( $\mathrm{T}-18$ Basic ULTRA TURRAX, IKA $\left.{ }^{\circledR}\right)$ in $5 \mathrm{ml}$ of TRIzol reagent. 1.5 $\mathrm{ml}$ of chloroform (Sigma, Ireland) was added to the TRIzol extract, mixed by inversion and incubated at room temperature for $3 \mathrm{~min}$. The sample was centrifuged at $11,500 \mathrm{~g}$ at $4^{\circ} \mathrm{C}$ for $15 \mathrm{~min}$. The aqueous phase containing RNA was transferred to a fresh tube and an equal volume of 2-propanol (Sigma, Ireland) was added. The sample was vortexed, incubated at room temperature for ten $\mathrm{min}$ and then centrifuged at $11,500 \mathrm{~g}$ at $4^{\circ} \mathrm{C}$ for $10 \mathrm{~min}$, resulting in the precipitation of the RNA out of solution in the form of a pellet. The supernatant was then removed, 70\% ETOH was added, and the sample was vortexed and centrifuged at 9,250 g at $4^{\circ} \mathrm{C}$ for 5 min. The new supernatant was removed and the pellet was allowed to dry at room temperature. The final pellet was resuspended in $100 \mu$ Elution Solution supplied with the GenElute ${ }^{\mathrm{TM}}$ Mammalian Total RNA kit (Sigma, Ireland), and RNA purified using the kit following the manufacturer's instructions. DNase treatment was performed using an On-column DNase (Sigma, Ireland) at a concentration of $70 \mu \mathrm{l}$ of DNase Digest Buffer for Oncolumn DNase Digestion to $10 \mu \mathrm{l}$ of DNase I. Total RNA was quantified and integrity assessed on an Agilent 2100 Bioanalyzer using the Agilent RNA 6000 Nano Chip kit. cDNA was synthesised for $3 \mu$ g of RNA using the Evrogen SMART cDNA synthesis service (Evrogen, Russia). $5 \mu \mathrm{g}$ of cDNA from each sample was used to create a Roche 454 sequencing library and sequenced on a Roche 454 Life Sciences GS FLX Titanium Series sequencer. The six $B$. terrestris samples were sequenced independently (one sample per lane), and base calling and quality screening performed using standard Roche pipeline version 2.3. Roche $454 \mathrm{sff}$ files were deposited in the SRA on the EBI, library ERP000936.

\section{Transcriptome assembly}

Roche 454 reads from the individual life cycle stages were combined to the purpose of assembly. We assembled the reads into a first draft transcriptome for $B$. terrestris following the approach of Kumar and Blaxter [41]. Two distinct assemblers were used to generate primary assemblies: gsAssembler from Roche/454 Life Sciences (also known as Newbler, version 2.5.3; with settings "-urt", "-cDNA", "-vt SMARTAdaptors.fna") (the Newbler_454 assembly), and MIRA (version 3.0.2;[84,85] (the MIRA_454 assembly). For MIRA assembly (settings: “-job=denovo,est,normal, 454"), SMART adaptors were removed using BLAST and a custom perl script.

The B. terrestris Sanger-sequenced expressed sequence tag (EST) data (generated by Sadd et al. [31]) and other pre-existing $B$. terrestris mRNAs in EMBL/GenBank were downloaded from EMBL nucleotide database (18th
August 2010), and assembled using PartiGene [86](the PG_Sanger assembly).

We then coassembled the three contig sets (PG_Sanger, Newbler_454 and MIRA_454) using CAP3 [87](with settings: sequence similarity $98 \%$ and base overlap $50 \mathrm{bp}$ ), to generate BT_transcriptome_v1 contigs. Examination of the BT_transcriptome_v1 contigs both affirmed that the assembly generated contig sequences of higher credibility than from the single assemblers, but also identified issues of remaining redundancy in the data. We therefore reclustered the $\mathrm{BT}_{-}$transcriptome_v1 contig set using PartiGene to generate the final $B$. terrestris transcriptome assembly, BT_transcriptome_v2, for annotation and analysis. We mapped each of the input reads in the Roche 454 data back to this final BT_transcriptome_v2 assembly using BLAST and assessed stage-specific expression of each contig by counting reads per contig for each source library using a custom Perl script. The vast majority of the total reads $(1,441,743$ ESTs or $92.4 \%)$ were mapped to 33,875 BT_transcriptome_v2 contigs.

\section{Assessment of completeness and integrity of the assembly}

We assessed the quality of BT_transcriptome_v2 by: (a) assessing congruence with available $B$. terrestris transcriptome shotgun assembly data from [32] (INDC Accession numbers: JI045408-JI025924.1) using BLAST [88]; and (b) assessing completeness compared to the whole-genome derived transcriptomes for other Hymenoptera (the official gene set (OGS) for the honeybee $A$. mellifera (from [89]), and the ants C. floridanus [NCBI Genome Project ID: 50201] and H. saltator [NCBI Genome Project ID: 50203]) and other arthropods (the OGS for $D$. melanogaster from the latest genome release [90]), using tBLASTx with an E-value cutoff of 1e-10.

\section{Functional Annotation}

We annotated the BT_transcriptome_v2 contigs with best BLAST matches by comparing them to the NCBI nr database (27th March 2011; reporting up to five matches with an E-value cutoff of 1e-06). BT_transcriptome_v2 contigs were also annotated with Gene Ontology (GO), Enzyme Commission (EC) and Kyoto Encyclopaedia of Genes and Genomes pathways (KEGG) identifiers using annot8r (v.1.1.1; $[91,92])$ with a cut-off bit score of 55 . GO terms were further summarised using the GO-Slim hierarchy. InterProScans were performed to infer putative function for hypothetical and unannotated contigs using Blast2GO software tool (V.2.4.8;[93-95]).

The annotated data were searched for genes, pathways and processes of interest. Gene lists were generated based on annotated processes and pathways for the eusocial honeybee, A. mellifera, the parasitoid jewel 
wasp, $N$. vitripennis, the holometabolous fruit fly, $D$. melanogaster, and the hemimetabolous pea aphid, $A$. pisum. Protein and nucleotide sequences of genes of interest were obtained from NCBI and compared to the $B$. terrestris transcriptome data using BLAST. Gene names and accession numbers used for these comparisons are given in Additional file 4.

\section{Comparison of expression between life stages of $B$. terrestris}

R-STAT analysis devised by Stekel et al. [42], was used to identify contigs in BT_transcriptome_v2 that varied in their proportional contribution from each of the six sequenced samples. R-STAT calculates a log likelihood ratio statistic that estimates variation of proportional contribution to each contig from each sample. The resulting statistic, the $\mathrm{R}$-value, expresses the variation in read contribution to each contig across life cycle stages. We treat the results from this study as preliminary because, given the absence of replication within life cycle stages and castes, these categories are confounded with the age of the individual specimens. Statistical analyses were carried out using the $\mathrm{R}$ language (version 2.11.1;[96]).

\section{Additional material}

\section{Additional file 1: Assembly pipeline of Bombus terrestris}

transcriptome. This excel file contains all information regarding raw read data, primary assemblies and secondary assemblies for generation of BT_transcriptome_v2

Additional file 2: Credibility testing of $\mathbf{4 5 4}$ versus Sanger data. This pdf data contains information on proportion of secondary assembly generated from 454 and/or Sanger data and in addition, credibility tests on unassembled Sanger data.

Additional file 3: GoSlim analyses of BT_transcriptome_v2. This excel file contains GO terms mapped to the BT_transcriptome_v2 contig set with individual pie-charts displaying contigs annotated with molecular function (MF), biological processes (BP) and cellular component (CC) ontologies.

Additional file 4: Gene sets for pathways and processes across the insect groups. This excel file contains gene sets of peptide sequences generated for A. mellifera, N. vitripennis, D. melanogaster and A. pisum.

Additional file 5: Singletons and contigs receiving unique EST contribution from a life cycle stage. This excel file contains information on number of unique singletons (sequences with one 454 read mapped), number of unique contigs (sequences with more than one 454 read mapped), number of ESTs contributed per life cycle stage to unique contig, total number of ESTs per life cycle stage, percentage of total ESTs from each life cycle stage contributed to unique contigs and percentage of total contig set for each group of stage-restricted contigs.

Additional file 6: Elevated expression within the individual life cycle stages. This pdf contains information on the top ten highly expressed contigs that best distinguish a life cycle stage.

\section{Acknowledgements}

We acknowledge Keelin Macdonald (Trinity College Dublin) for help with maintenance of animals, Luke McNally (Trinity College Dublin) for statistical assistance and colleagues at the University of Edinburgh for computational advice and assistance: Sujai Kumar, Emanuel Heitlinger, Ben Elsworth and Tim Cezard. We also acknowledge cDNA synthesis performed by Evrogen, Russia, and library preparation and 454 sequencing performed by Anna Montazam and Denis Cleven, of the GenePool Facility, Edinburgh. This publication has emanated from research conducted with the financial support of Science Foundation Ireland.

\section{Author details}

${ }^{1}$ Department of Zoology, School of Natural Sciences, Trinity College Dublin, Dublin 2, Ireland. 'Department of Biology, Callan Building, National University of Ireland Maynooth, Maynooth, Co. Kildare, Ireland. ${ }^{3}$ The GenePool Genomics Facility, School of Biological Sciences, University of Edinburgh, West Mains Road, Edinburgh EH9 3JT, UK. Institute of Zoology, Zoological Society of London, Regent's Park, London, NW1 4RY, UK. ${ }^{5}$ Institute of Evolutionary Biology, University of Edinburgh, West Mains Road, Edinburgh EH9 3JT, UK. 'SChool of Biological Sciences, Royal Holloway, University of London, Egham, Surrey, TW20 OEX, UK.

\section{Authors' contributions}

TJC collected samples, isolated RNA and conducted the bioinformatics analysis of the contig set. JCC, SJB and MLB were involved in assembly and annotation of the contig set. The study was conceived and designed by SS MLB and MJFB. All authors were involved in the writing of the manuscript. All authors have read and approved the final manuscript.

Received: 22 July 2011 Accepted: 20 December 2011 Published: 20 December 2011

\section{References}

1. West-Eberhard MJ: Phenotypic plasticity and the origins of diversity. In Annual Review of Ecology and Systematics, Vol 20 Ix+477p Annual Reviews Inc: Palo Alto, California, USA Illus Maps Edited by: Johnston RF 1989, 249-278.

2. Agrawal AA: Ecology - Phenotypic plasticity in the interactions and evolution of species. Science 2001, 294(5541):321-326.

3. Schlichting CD: Phenotypic plasticity in plants. Plant Species Biology 2002, 17(2-3):85-88

4. Evans JD, Wheeler DE: Gene expression and the evolution of insect polyphenisms. Bioessays 2001, 23(1):62-68.

5. Mayhew PJ: A tale of two analyses: estimating the consequences of shifts in hexapod diversification. Biological Journal of the Linnean Society 2003, 80(1):23-36.

6. Wilson EO: The Insect Societies. The Belknap Press of Harvard University Press 1971

7. Watson JAL, Okot-Kotber BM, Noirot C: Caste differentiation in social insects. (Current themes in tropical science, v3) Pergamon Press Ltd 1985.

8. Hamilton WD: The genetical evolution of social behavior. Journal of Theoretical Biology 1964, 7:1-16.

9. Cook JM: Sex determination in the Hymenoptera - A review of models and evidence. Heredity 1993, 71:421-435.

10. Evans JD, Wheeler DE: Differential gene expression between developing queens and workers in the honey bee, Apis mellifera. Proceedings of the National Academy of Sciences of the United States of America 1999, 96(10):5575-5580.

11. Pereboom JJM, Jordan WC, Sumner S, Hammond RL, Bourke AFG: Differential gene expression in queen-worker caste determination in bumble-bees. Proceedings of the Royal Society B-Biological Sciences 2005, 272(1568):1145-1152.

12. Sumner S, Pereboom JJM, Jordan WC: Differential gene expression and phenotypic plasticity in behavioural castes of the primitively eusocial wasp, Polistes canadensis. Proceedings of the Royal Society B: Biological Sciences 2006, 273(1582):19-26.

13. Graff J, Jemielity S, Parker JD, Parker KM, Keller L: Differential gene expression between adult queens and workers in the ant Lasius niger. Molecular Ecology 2007, 16(3):675-683.

14. Hoffman EA, Goodisman MAD: Gene expression and the evolution of phenotypic diversity in social wasps. BMC Biology 2007, 5(1):23.

15. Hunt JH, Wolschin F, Henshaw MT, Newman TC, Toth AL, Amdam GV: Differential gene expression and protein abundance evince ontogenetic bias toward castes in a primitively eusocial wasp. PLOS ONE 2010, 5(5). 
16. Grozinger CM, Fan Y, Hoover SER, Winston ML: Genome-wide analysis reveals differences in brain gene expression patterns associated with caste and reproductive status in honey bees (Apis mellifera). Molecular Ecology 2007, 16(22):4837-4848.

17. Baratte S, Peeters C, Deutsch JS: Testing homology with morphology, development and gene expression: sex-specific thoracic appendages of the ant Diacamma. Evolution \& Development 2006, 8(5):433-445.

18. Gempe T, Hasselmann M, Schiott M, Hause G, Otte M, Beye M: Sex determination in honeybees: Two separate mechanisms induce and maintain the female pathway. PLoS Biology 2009, 7(10)

19. Colonello-Frattini NA, Guidugli-Lazzarini KR, Simoes ZLP, Hartfelder K: Mars is close to Venus - Female reproductive proteins are expressed in the fat body and reproductive tract of honey bee (Apis mellifera L.) drones. Journal of Insect Physiology 2010, 56(11):1638-1644.

20. Margulies M, Egholm M, Altman WE, Attiya S, Bader JS, Bemben LA, Berka J, Braverman MS, Chen YJ, Chen ZT, et al: Genome sequencing in microfabricated high-density picolitre reactors. Nature 2005, 437(7057):376-380.

21. Wicker T, Schlagenhauf E, Graner A, Close TJ, Keller B, Stein N: 454 sequencing put to the test using the complex genome of barley. BMC Genomics 2006, 7.

22. Vera JC, Wheat CW, Fescemyer HW, Frilander MJ, Crawford DL, Hanski I, Marden $\mathrm{JH}$ : Rapid transcriptome characterization for a nonmodel organism using 454 pyrosequencing. Molecular Ecology 2008, 17(7):1636-1647

23. O'Neil ST, Dzurisin JDK, Carmichael RD, Lobo NF, Emrich SJ, Hellmann JJ: Population-level transcriptome sequencing of nonmodel organisms Erynnis propertius and Papilio zelicaon. BMC Genomics 2010, 11.

24. Chen S, Yang P, Jiang F, Wei $Y, M a Z$, Kang $L$ : De novo analysis of transcriptome dynamics in the migratory locust during the development of phase traits. PLOS ONE 2010, 5(12).

25. Toth AL, Varala K, Henshaw MT, Rodriguez-Zas SL, Hudson ME, Robinson GE: Brain transcriptomic analysis in paper wasps identifies genes associated with behaviour across social insect lineages. Proceedings of the Royal Society B: Biological Sciences 2010, 277(1691):2139-2148

26. Alford DV: Bumblebees. Davis-Poynter, London 1975

27. Goulson D: Bumblebees; their behaviour and ecology. Oxford University Press, Oxford 2003.

28. Velthuis HHW, van Doorn A: A century of advances in bumblebee domestication and the economic and environmental aspects of its commercialization for pollination. Apidologie 2006, 37(4):421-451.

29. Pendrel BA, Plowright RC: Larval feeding by adult bumble bee workers (Hymenoptera, Apidae). Behavioral Ecology and Sociobiology 1981, 8(2):71-76

30. Goulson D: Can alloethism in workers of the bumblebee, Bombus terrestris, be explained in terms of foraging efficiency? Animal Behaviour 2002, 64(1):123-130.

31. Sadd BM, Kube M, Klages S, Reinhardt R, Schmid-Hempel P: Analysis of a normalised expressed sequence tag (EST) library from a key pollinator, the bumblebee Bombus terrestris. BMC Genomics 2010, 11.

32. Woodard SH, Fischman BJ, Venkat A, Hudson ME, Varala K, Cameron SA, Clark AG, Robinson GE: Genes involved in convergent evolution of eusociality in bees. Proceedings of the National Academy of Sciences of the United States of America 2011, 108(18):7472-7477.

33. Schmid-Hempel P: Parasites in social insects. Published by Princeton MBE 1998

34. Baer B: Bumblebees as model organisms to study male sexual selection in social insects. Behavioral Ecology and Sociobiology 2003, 54(6):521-533.

35. O'Donnell S, Beshers SN: The role of male disease susceptibility in the evolution of haplodiploid insect societies. Proceedings of the Royal Society of London Series B-Biological Sciences 2004, 271(1542):979-983.

36. Ruiz-Gonzalez MX, Brown MJF: Males vs workers: testing the assumptions of the haploid susceptibility hypothesis in bumblebees. Behavioral Ecology and Sociobiology 2006, 60(4):501-509.

37. Getz WM, Chapman RF: An odor discrimination model with application to kin recognition in social insects. International Journal of Neuroscience 1987, 32(3-4):963-978.

38. Kunze J, Gumbert A: The combined effect of color and odor on flower choice behavior of bumble bees in flower mimicry systems. Behavioral Ecology 2001, 12(4):447-456.
39. Cnaani J, Robinson GE, Bloch G, Borst D, Hefetz A: The effect of queenworker conflict on caste determination in the bumblebee Bombus terrestris. Behavioral Ecology and Sociobiology 2000, 47(5):346-352.

40. Ayasse M, Paxton RJ, Tengo J: Mating behavior and chemical communication in the Order Hymenoptera. Annual Review of Entomology 2001, 46:31-78.

41. Kumar S, Blaxter ML: Comparing de novo assemblers for 454 transcriptome data. BMC Genomics 2010, 11.

42. Stekel DJ, Git Y, Falciani F: The comparison of gene expression from multiple cDNA libraries. Genome Research 2000, 10(12):2055-2061.

43. Persson B, Kallberg Y, Bray JE, Bruford E, Dellaporta SL, Favia AD, Duarte RG, Jörnvall H, Kavanagh KL, Kedishvili N: The SDR (short-chain dehydrogenase/reductase and related enzymes) nomenclature initiative. Chemico-Biological Interactions 2009, 178(1-3):94-98.

44. Guidugli KR, Hepperle C, Hartfelder K: A member of the short-chain dehydrogenase/reductase (SDR) superfamily is a target of the ecdysone response in honey bee (Apis mellifera) caste development. Apidologie 2004, 35(1):37-47.

45. Burmester T, Massey HC, Zakharkin SO, Benes H: The evolution of hexamerins and the phylogeny of insects. Journal of Molecular Evolution 1998, 47(1):93-108.

46. Telfer WH, Kunkel JG: The function and evolution of insect storage hexamers. Annual Review of Entomology 1991, 36:205-228.

47. Jones G, Brown N, Manczak M, Hiremath S, Kafatos FC: Molecular cloning, regulation, and complete sequence of a hemocyanin-related, juvenile hormone-suppressible protein from insect hemolymph. Journal of Biological Chemistry 1990, 265(15):8596-8602.

48. Braun RP, Wyatt GR: Sequence of the hexameric juvenile hormonebinding protein from the hemolymph of Locusta migratoria. Journal of Biological Chemistry 1996, 271(49):31756-31762.

49. Zhou XG, Tarver MR, Scharf ME: Hexamerin-based regulation of juvenile hormone-dependent gene expression underlies phenotypic plasticity in a social insect. Development 2007, 134(3):601-610.

50. Cunha AD, Nascimento AM, Guidugli KR, Simoes ZLP, Bitondi MMG: Molecular cloning and expression of a hexamerin CDNA from the honey bee, Apis mellifera. Journal of Insect Physiology 2005, 51(10):1135-1147.

51. Bitondi MMG, Nascimento AM, Cunha AD, Guidugli KR, Nunes FMF, Simoes ZLP: Characterization and expression of the Hex 110 gene encoding a glutamine-rich hexamerin in the honey bee, Apis mellifera. Archives of Insect Biochemistry and Physiology 2006, 63(2):57-72.

52. Martins JR, Nunes FMF, Simoes ZLP, Bitondi MMG: A honeybee storage protein gene, hex 70a, expressed in developing gonads and nutritionally regulated in adult fat body. Journal of Insect Physiology 2008, 54(5):867-877

53. Martins JR, Nunes FMF, Cristino AS, Simoes ZP, Bitondi MMG: The four hexamerin genes in the honey bee: structure, molecular evolution and function deduced from expression patterns in queens, workers and drones. BMC Molecular Biology 2010, 11.

54. Hunt JH, Kensinger BJ, Kossuth JA, Henshaw MT, Norberg K, Wolschin F, Amdam GV: A diapause pathway underlies the gyne phenotype in Polistes wasps, revealing an evolutionary route to caste-containing insect societies. Proceedings of the National Academy of Sciences of the United States of America 2007, 104(35):14020-14025.

55. Martinez T, Wheeler DE: Storage proteins in adult ants (Camponotus festinatus) - roles in colony founding by queens and in larval rearing by workers. Journal of Insect Physiology 1994, 40(8):723-729.

56. Johnston ML, Wheeler DE: The role of storage proteins in colonyfounding in termites. Insectes Sociaux 2007, 54(4):383-387.

57. Williams $\mathrm{PH}$, Osborne $\mathrm{J}$ : Bumblebee vulnerability and conservation world-wide. Apidologie 2009, 40(3):367-387.

58. Ohashi K, Sawata M, Takeuchi H, Natori S, Kubo T: Molecular cloning of cDNA and analysis of expression of the gene for alpha-glucosidase from the hypopharyngeal gland of the honeybee Apis mellifera L. Biochemical and Biophysical Research Communications 1996, 221(2):380-385.

59. Hu Z, Wang D, Lu W, Cui Z, Jia JM, Yoon HJ, Sohn HD, Kim DH, Jin BR: Molecular cloning and characterisation of a muscle-specific lipase from the bumblebee Bombus ignitus. Int J Indust Entomol 2008, 17(1):143-151.

60. Robinson GE: Regulation of division of labor in insect societies. Annual Review of Entomology 1992, 37:637-665. 
61. Cameron SA: Temporal patterns of division of labor among workers in the primitively eusocial bumble bee, Bombus griseocollis (Hymenoptera, Apidae). Ethology 1989, 80(1-4):137-151.

62. Hu DH, Matsuno A, Terakado K, Matsuura T, Kimura S, Maruyama K: Projectin is an invertebrate connectin (titin) - isolation from crayfish claw muscle and localization in crayfish claw muscle and insect flight muscle. Journal of Muscle Research and Cell Motility 1990, 11(6):497-511.

63. Li B, Predel R, Neupert S, Hauser F, Tanaka Y, Cazzamali G, Williamson M, Arakane $Y$, Verleyen $P$, Schoofs $L$, et al: Genomics, transcriptomics, and peptidomics of neuropeptides and protein hormones in the red flour beetle Tribolium castaneum. Genome Research 2008, 18(1):113-122.

64. Badisco L, Claeys I, Van Loy T, Van Hiel M, Franssens V, Simonet G, Broeck JV: Neuroparsins, a family of conserved arthropod neuropeptides. General and Comparative Endocrinology 2007, 153(1-3):64-71.

65. Schmid-Hempel R, Schmid-Hempel P: Female mating frequencies in Bombus spp. from Central Europe. Insectes Sociaux 2000, 47(1):36-41.

66. Tasei JN, Moinard C, Moreau L, Himpens B, Guyonnaud S: Relationship between aging, mating and sperm production in captive Bombus terrestris. Journal of Apicultural Research 1998, 37(2):107-113.

67. Beekman M, van Stratum P: Bumblebee sex ratios: why do bumblebees produce so many males? Proceedings of the Royal Society of London Series B-Biological Sciences 1998, 265(1405):1535-1543.

68. Ahmed AM, Baggott SL, Maingon R, Hurd H: The costs of mounting an immune response are reflected in the reproductive fitness of the mosquito Anopheles gambiae. Oikos 2002, 97(3):371-377.

69. Casteels P, Ampe C, Jacobs F, Tempst P: Functional and chemical characterization of hymenoptaecin, an antibacterial polypeptide that is infection-inducible in the honeybee (Apis mellifera). Journal of Biological Chemistry 1993, 268(10):7044-7054.

70. Li WF, Ma GX, Zhou XX: Apidaecin-type peptides: Biodiversity, structurefunction relationships and mode of action. Peptides 2006, 27(9):2350-2359.

71. Choi YS, Choo YM, Lee KS, Yoon HJ, Kim I, Je YH, Sohn HD, Jin BR: Cloning and expression profiling of four antibacterial peptide genes from the bumblebee Bombus ignitus. Comparative Biochemistry and Physiology BBiochemistry \& Molecular Biology 2008, 150(2):141-146.

72. Beckage NE: Insect Immunology. Published by Academic Press. 2008

73. Wilfert L, Gadau J, Schmid-Hempel P: The genetic architecture of immune defense and reproduction in male Bombus terrestris bumblebees. Evolution 2007, 61(4):804-815.

74. Cremer S, Armitage SAO, Schmid-Hempel P: Social immunity. Current Biology 2007, 17(16):R693-R702.

75. Foret S, Maleszka R: Function and evolution of a gene family encoding odorant binding-like proteins in a social insect, the honey bee (Apis mellifera). Genome Research 2006, 16:1404-1413.

76. Danty E, Arnold G, Huet JC, Huet D, Masson C, Pernollet JC: Separation, characterization and sexual heterogeneity of multiple putative odorantbinding proteins in the honeybee Apis mellifera L. (Hymenoptera: Apidea). Chemical Senses 1998, 23(1):83-91.

77. Forêt S, Wanner KW, Maleszka R: Chemosensory proteins in the honey bee: Insights from the annotated genome, comparative analyses and expressional profiling. Insect Biochemistry and Molecular Biology 2007, 37(1):19-28.

78. Briand L, Swasdipan N, Nespoulous C, Bezirard V, Blon F, Huet JC, Ebert P, Pernollet JC: Characterization of a chemosensory protein (ASP3C) from honeybee (Apis mellifera L.) as a brood pheromone carrier. European Journal of Biochemistry 2002, 269(18):4586-4596.

79. Toth AL, Varala K, Newman TC, Miguez FE, Hutchison SK, Willoughby DA, Simons JF, Egholm M, Hunt JH, Hudson ME, et al: Wasp gene expression supports an evolutionary link between maternal behavior and eusociality. Science 2007, 318(5849):441-444

80. Wilfert L, Gadau J, Schmid-Hempel P: A core linkage map of the bumblebee Bombus terrestris. Genome 2006, 49(10):1215-1226.

81. Wilfert L, Torres MM, Reber-Funk C, Schmid-Hempel R, Tomkins J, Gadau J, Schmid-Hempel P: Construction and characterization of a BAC-library for a key pollinator, the bumblebee Bombus terrestris L. Insectes Sociaux 2009, 56(1):44-48.

82. Stolle E, Wilfert L, Schmid-Hempel R, Schmid-Hempel P, Kube M, Reinhardt R, Moritz RFA: A second generation genetic map of the bumblebee Bombus terrestris (Linnaeus, 1758) reveals slow genome and chromosome evolution in the Apidae. BMC Genomics 2011, 12.
83. [http://www.nematodes.org/NeglectedGenomes/ARTHROPODA/ Bombus_terrestris/].

84. [http://sourceforge.net/apps/mediawiki/mira-assembler].

85. Chevreux B, Pfisterer T, Drescher B, Driesel AJ, Muller WEG, Wetter T, Suhai S: Using the miraEST assembler for reliable and automated mRNA transcript assembly and SNP detection in sequenced ESTs. Genome Research 2004, 14(6):1147-1159.

86. Parkinson J, Anthony A, Wasmuth J, Schmid R, Hedley A, Blaxter M: PartiGene - constructing partial genomes. Bioinformatics 2004, 20(9):1398-1404.

87. Huang $X Q$, Madan A: CAP3: A DNA sequence assembly program. Genome Research 1999, 9(9):868-877.

88. Altschul SF, Gish W, Miller W, Myers EW, Lipman DJ: Basic local alignment search tool. Journal of Molecular Biology 1990, 215(3):403-410.

89. [http://hymenopteragenome.org/beebase/].

90. [ftp://ftp.flybase.net/genomes/Drosophila_melanogaster/].

91. [http://www.nematodes.org/bioinformatics/annot8r/index.shtml].

92. Schmid R, Blaxter ML: annot8r: GO, EC and KEGG annotation of EST datasets. BMC Bioinformatics 2008, 9.

93. [http://www.blast2go.org/].

94. Conesa A, Gotz S: Blast2GO: A comprehensive suite for functional analysis in plant genomics. Int J Plant Genomics 2008, 2008:619832.

95. Gotz S, Garcia-Gomez JM, Terol J, Williams TD, Nagaraj SH, Nueda MJ, Robles M, Talon M, Dopazo J, Conesa A: High-throughput functional annotation and data mining with the Blast2GO suite. Nucleic Acids Research 2008, 36(10):3420-3435.

96. [http://www.r-project.org/].

\section{doi:10.1186/1471-2164-12-623}

Cite this article as: Colgan et al:: Polyphenism in social insects: insights from a transcriptome-wide analysis of gene expression in the life stages of the key pollinator, Bombus terrestris. BMC Genomics 2011 12:623.

\section{Submit your next manuscript to BioMed Central and take full advantage of:}

- Convenient online submission

- Thorough peer review

- No space constraints or color figure charges

- Immediate publication on acceptance

- Inclusion in PubMed, CAS, Scopus and Google Scholar

- Research which is freely available for redistribution

Submit your manuscript at www.biomedcentral.com/submit
C Biomed Central 